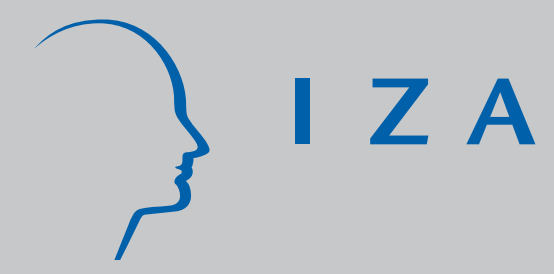

IZA DP No. 1955

Indirect Effects of an Aid Program:

The Case of Progresa and Consumption

Manuela Angelucci

Giacomo De Giorgi

J anuary 2006 


\title{
Indirect Effects of an Aid Program: The Case of Progresa and Consumption
}

\author{
Manuela Angelucci \\ University of Arizona \\ and IZA Bonn \\ Giacomo De Giorgi \\ University College London
}

\author{
Discussion Paper No. 1955 \\ January 2006
}

\author{
IZA \\ P.O. Box 7240 \\ 53072 Bonn \\ Germany \\ Phone: +49-228-3894-0 \\ Fax: +49-228-3894-180 \\ Email: iza@iza.org
}

\begin{abstract}
Any opinions expressed here are those of the author(s) and not those of the institute. Research disseminated by IZA may include views on policy, but the institute itself takes no institutional policy positions.

The Institute for the Study of Labor (IZA) in Bonn is a local and virtual international research center and a place of communication between science, politics and business. IZA is an independent nonprofit company supported by Deutsche Post World Net. The center is associated with the University of Bonn and offers a stimulating research environment through its research networks, research support, and visitors and doctoral programs. IZA engages in (i) original and internationally competitive research in all fields of labor economics, (ii) development of policy concepts, and (iii) dissemination of research results and concepts to the interested public.
\end{abstract}

IZA Discussion Papers often represent preliminary work and are circulated to encourage discussion. Citation of such a paper should account for its provisional character. A revised version may be available directly from the author. 


\section{ABSTRACT \\ Indirect Effects of an Aid Program: The Case of Progresa and Consumption*}

Aid programs in developing countries are likely to affect all households living in the treated areas, both eligible and non-eligible ones. Studies that focus on the treatment effect on the treated may fail to capture important spillover effects. We exploit the unique design of an aid program's experimental trial to identify its indirect effect on consumption for non-eligible households living in treated areas. We find that this effect is positive, and that it occurs through changes in the insurance and credit markets: non-eligible households receive more transfers, and borrow more when hit by a negative idiosyncratic shock, because of the program liquidity injection, thus they can reduce their precautionary savings. We also test for general equilibrium effects in the local labor and goods markets, finding no significant changes in labor income and prices, while there is a reduction in earnings from sales of agricultural products, which are now consumed. We show that this class of aid programs has important positive externalities, thus their overall effect is larger than the effect on the treated. Our results confirm that a key identifying assumption - that the treatment has no effect on the non-treated - is likely to be violated in similar policy designs.

JEL Classification: E21, H43, I38, O12, O17

Keywords: program evaluation, consumption, Progresa

Corresponding author:

Giacomo De Giorgi

University College London

Department of Economics

Drayton House, Gordon Street

London WC1H OAX

United Kingdom

Email: g.degiorgi@ucl.ac.uk

\footnotetext{
* We are grateful to Orazio Attanasio, Richard Blundell, Price Fishback, Kei Hirano, Costas Meghir, Nicola Pavoni, Imran Rasul, Adam Szeidl, Andreas Uthermann as well as seminar participants at Universidad Autonoma Barcelona, University of Alicante, University College London, and University of Arizona. The usual disclaimer applies.
} 


\section{Introduction}

Policy interventions in developing countries are likely to affect all residents of the areas where they are implemented, especially when village economies and social networks create strong links between a limited number of households. However, the program evaluation literature is mainly focused on estimating the program effects on the treated, rather than the effects on the nontreated or general equilibrium effects. In this paper, we exploit the unique design of Progresa's experimental trial to estimate its indirect effect on consumption for non-eligible households who live in treatment areas, and to understand the mechanisms through which this indirect effect occurs. We show that liquidity injections into small rural communities increase the consumption of the non-treated through changes in the credit and insurance markets. Thus, the total effect of Progresa in these communities is larger than its effect on the treated. Our results confirm that a key identifying assumption - that the program has no effect on non-treated individuals - is likely to be violated in similar policy designs.

Conditional cash transfers are a popular type of aid program, which provides monetary transfers to eligible recipients, provided they send their children to school, attend nutrition classes, and have periodic health checks. Programs with this format are currently implemented in numerous countries: Bangladesh, Bolivia, Brazil, Colombia, Honduras, Jamaica, Mexico, and Nicaragua. Progresa is an ongoing conditional cash transfer program targeted at Mexican poor rural households, providing grants to improve education, health, and nutrition.

The design of the experimental trial and the data collected for the evaluation have some unique features. First, the randomization was implemented at the village level. Second, program administrators collected data on all households, both poor and non-poor, although only poor households were eligible for the treatment. Thus, we have information on four groups: poor and non-poor households in treatment and control villages. Non-poor households in control villages provide a valid counterfactual for the non-poor in treatment ones, under the assumptions that assignment is truly random, and that control villages are not indirectly affected by the program. Hence, this particular experimental design enables us to estimate the indirect effects of the program on non-eligible households who live in treatment areas using fairly standard identifying assumptions.

We focus on consumption because it provides a synthetic measure of household well-being. We find that there is a positive, significant indirect program effect on consumption for noneligible families. This effect is quite sizeable, as it is as big as two thirds of the increase in consumption for the poor, in absolute level. Further, we study the mechanisms that permit this 
increase in consumption. For example, the implementation of Progresa may modify the labor supply, altering equilibrium wages, or it may increase goods prices through a higher demand. We find that there are no significant indirect effects on labor earnings, prices (with the exception of increases in few food items in 1998), and welfare receipt, and that sales of agricultural products decrease. Therefore, we rule out the hypothesis that the indirect program effect on consumption is generated by an increase in current income. Instead, we show that non-poor households in treatment villages consume more by receiving more transfers, by borrowing more money - almost exclusively from family, friends, or informal moneylenders - and by reducing their stocks of grains and animals. In addition, we show that the indirect program effects on consumption and loans are larger for households hit by a negative idiosyncratic shock. Thus, we conclude that cash transfers in treatment villages indirectly benefit non-treated households by improving consumption smoothing. These results correspond to our knowledge of developing countries, where credit and insurance occur through informal networks of family, friends, and neighbors. Positive income shocks to some households benefit the whole network, whose other members receive larger loans and transfers, especially the ones hit by negative shocks. The availability of additional liquidity in the network enables households to reduce their savings.

While it is often difficult to predict the effects of a nationwide program using data from limited geographic areas, the effects on the credit and insurance market should not be a function of the number of treated villages, as long as social networks are village-specific. Hence, we can predict positive indirect effects on consumption occurring through changes in local credit and insurance arrangements. ${ }^{1}$ Thus, the indirect effects reinforce the direct ones in this class of policies, unlike in many active labor market programs. ${ }^{2}$

By estimating significant indirect treatment effects, this paper provides a very clear example of the violation of the stable unit treatment value assumption (SUTVA). SUTVA states that potential outcomes depend on the treatment received, and not on what treatments other units receive (Rubin, 1986), ruling out any effect of the program on non-treated households. As such, our exercise highlights the importance of carefully considering the type of data available and the policy at hand before implementing partial equilibrium estimators. For example, when the distance (economic, social or geographic) between treatment and control group is small, and when the treatment group is a large fraction of the local economy, the SUTVA may be less

\footnotetext{
${ }^{1}$ As regards the labor market, there should not be any major changes, as long as the decrease in child labor is minimal, compared to the size of the active labor force. The general equilibrium effect on goods prices is instead less clear.

${ }^{2}$ For example, Blundell et al. (2004) and De Giorgi (2005) discuss the possibility that subsidized employment for the treated group in the British New Deal program may generate a substitution effects between treated and control units.
} 
likely to hold.

In sum, the paper contributes to different literatures. We add to the literature that studies consumption smoothing and credit and insurance markets in low-income economies by showing the indirect effects of an exogenous liquidity injection. We also contribute to the program evaluation literature in multiple ways: first, we show that a class of widely implemented aid policies has important positive externalities, and we establish how they operate. ${ }^{3}$ Second, we try and extrapolate the indirect effects of a nationwide conditional cash transfer program in the credit and insurance market. Third, we provide an example of the failure of the SUTVA, which is normally non-testable, and we discuss cases in which this failure is likely to occur.

The paper is organized as follows: section 2 describes the structure of Progresa and the characteristics of the data collected for its evaluation. Section 3 discusses the identification of the parameters of interest. Section 4 presents the initial results. Section 5 analyzes the possible channels through which consumption increases. Section 6 investigates the role of idiosyncratic shocks on consumption and credit market. Section 7 concludes.

\section{Progresa: program structure and data characteristics}

Progresa is an ongoing program that targets Mexican poor households, providing grants to improve education, health, and nutrition. Started in 1998, by the end of 1999 this program had about 2.6 million recipient households in more than 2,000 municipalities, at a cost of approximately $0.2 \%$ of Mexico's GDP. Progresa provides grants in the form of nutritional subsidies, as well as scholarships for children attending third to ninth grade. The recipients of the transfers are women. Grants, paid bimonthly, are conditional upon family visits to health centers, women's participation in informal workshops on health and nutrition issues, and verification that children attended classes at least $85 \%$ of the time during the previous sixty days. Scholarships are larger for higher school grades and for females attending secondary school, the bimonthly amounts ranging between 160 pesos for third grade to 530 and 610 pesos for males and female in ninth grade, in November 1999. These payments correspond approximately to one half to two thirds of the wage a child would earn by working full time (Schultz, 2004), and cannot exceed a total of 1500 pesos per household (bimonthly), again in

\footnotetext{
${ }^{3}$ The literature on indirect effects can be roughly grouped into papers that use sources of exogenous variation to identify peer effects, and papers that set up and calibrate structural models to estimate general equilibrium effects. The first group includes Duflo and Saez (2002), Katz et al. (2001), Miguel and Kremer (2004), Philipson (2000) and Sacerdote (2001). Bobonis and Finan (2005) and Lalive and Cattaneo (2005) use Progresa data to estimate peer effects in schooling decisions. The second group includes, among others, Heckman et al. (1998) and Lise et al. (2005). Some important references in the risk-sharing literature are Deaton (1991), Banerjee et al. (2003), and Banerjee (2004), in addition to the ones we mention in the text.
} 
November 1999. ${ }^{4}$ The grants are quite large, corresponding to $20 \%$ of pre-program consumption.

The data for the evaluation of Progresa contain information on households from a subsample of 506 poor rural villages from seven different states. Information are recorded both before the program starts - in May 1998 - and during the first 18 months of its implementation. Eligibility depends on poverty status, and households are classified into poor and non-poor according to the information collected in the September 1997 census of localities. ${ }^{5}$ There were two rounds of selection of eligible households in Progresa. 52 percent of households were initially classified as poor in $1997 .{ }^{6}$ The households are informed that, after they are classified as poor and non-poor, their eligibility status will not change until November 1999, irrespective of any income variation. All residents of both control and treatment villages were then interviewed about every six months, in October 1998, May, and November 1999. This provides information from three different points in time after the beginning of the program, as well as pre-program data (from either the September 1997 census or the March 1998 wave, which collects data on the 506 sampled villages only).

An interesting feature of the data set is that 186 villages (about $36 \%$ of the sampled localities) were randomized out. Eligible households in control villages were not administered the program until the end of 1999. Thus, our data can be divided in four groups: poor and non-poor households in treatment and control villages. Only poor households in treatment areas receive the Progresa transfers. Poor households in control villages know that they will be included in the program at the end of 1999, provided that they are still poor and that the program is still in place. ${ }^{7}$ The structure of the data is shown in Figure 1. In the following section we discuss how we exploit this particular sample design to estimate the effect of the program on non-eligible households living in treatment villages, i.e. our indirect program effect parameter.

\footnotetext{
${ }^{4}$ The size of the scholarships were smaller in 1998 and have been adjusted to keep their real value constant.

${ }^{5}$ For a detailed discussion of the selection criteria both for villages and households see Skoufias et al., 1999b.

${ }^{6}$ The following year, almost half of the households initially classified as non-poor were added into the beneficiary group. However, most of this latter set of families did not receive the transfers for other exogenous reasons (administrative problems), irrespective of their compliance with the eligibility rules. For this reason, we restrict our sample to the households initially classified as poor when we estimate program effects on the treated.

${ }^{7}$ The existence of the program could not be guaranteed beyond 1999 because Progresa may have been discontinued by the new administration, after the 2000 general election.
} 


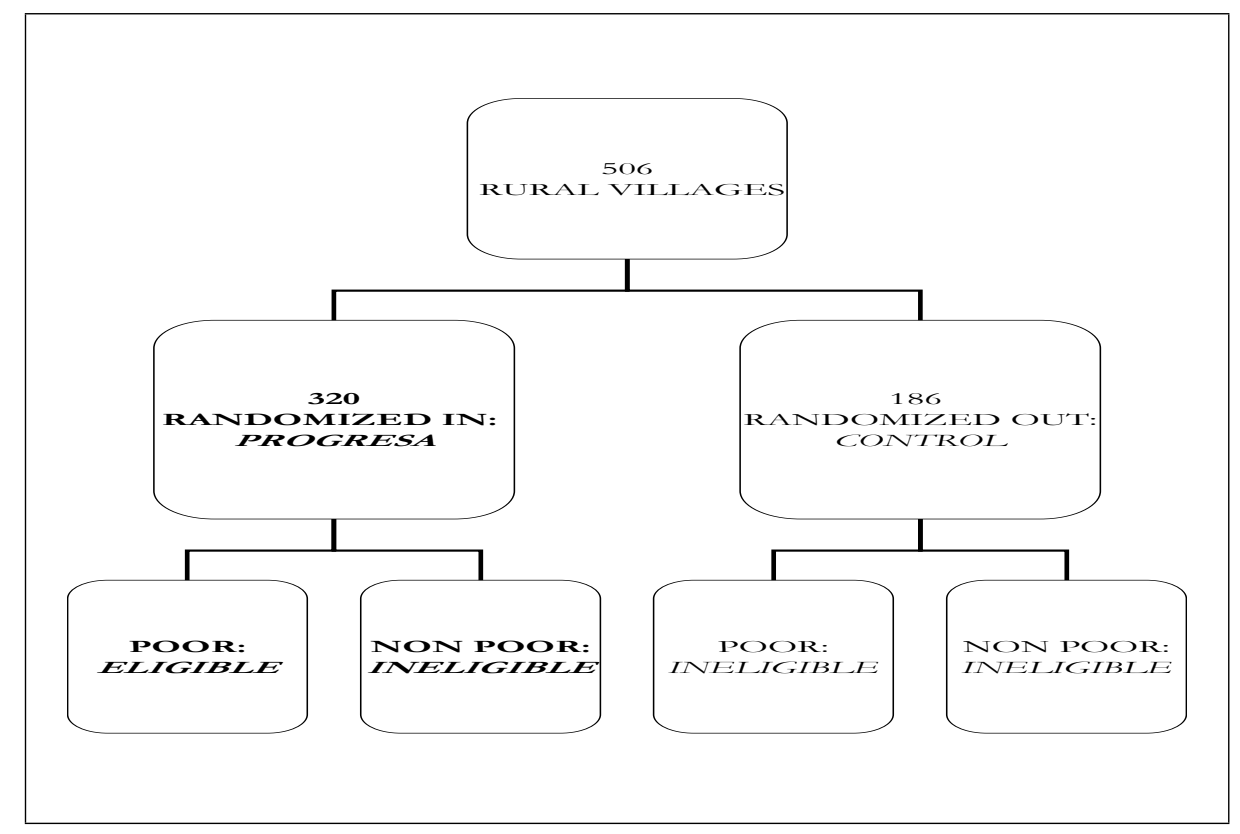

Figure 1: Design of the data for the evaluation of Progresa

\section{Identification}

Experimental data often consist of a sample of eligible individuals randomly assigned to the treatment or to the control group. ${ }^{8}$ Instead, the sample for the evaluation of Progresa has some important features that make its design unique: first, it is randomized at the village level. Second, it has data on all households, both poor and non-poor, although only poor households were eligible for the treatment. Thus, we have information on four groups: poor and non-poor households in treatment and control villages. Under the assumptions that the assignment is truly random, and that control villages are not affected by the program, poor in control areas provide a valid counterfactual for treated poor, and non-poor in control villages provide a counterfactual for non-poor in treatment villages. Therefore, we can estimate the indirect effect of Progresa on non-eligible households who live in the same locality as treated households using standard identification assumptions. We define this parameter below as the Indirect Treatment Effect (ITE). Estimating significant ITEs implies that the treatment affects potential outcomes of the ineligibles who live in treatment areas. This is a violation of the Stable Unit Treatment Value Assumption (SUTVA). Thus, the sample design enables us to indirect test the SUTVA at the locality level, which is not normally possible.

Formally, define $Y_{1 i}$ as the potential outcome for non-poor $\left(N P_{i}=1\right)$ in treatment villages $\left(T_{i}=1\right)$ in the presence of the treatment. $Y_{0 i}$ is the potential outcome for non-poor $\left(N P_{i}=1\right)$

\footnotetext{
${ }^{8}$ See, for example, the JTPA randomized trial as in Heckman and Smith (2004), or the evaluation of the GAIN project by Hotz et al. (2000).
} 
in treatment villages $\left(T_{i}=1\right)$ in the absence of the treatment. The observed outcome is: $Y_{i}=Y_{0 i}+T_{i}\left(Y_{1 i}-Y_{0 i}\right)$. The treatment is Progresa transfers to poor households $\left(N P_{i}=0\right)$ in treatment villages $\left(T_{i}=1\right)$. The ITE is the average effect of the program on non-poor households: ${ }^{9}$

$$
I T E=E\left(Y_{1 i}-Y_{0 i} \mid T_{i}=1, N P_{i}=1\right)=E\left(Y_{1 i} \mid T_{i}=1, N P_{i}=1\right)-E\left(Y_{0 i} \mid T_{i}=1, N P_{i}=1\right) .
$$

Since we do not observe the potential outcome in the absence of the treatment for non-poor households in treated communities, $E\left(Y_{0 i} \mid T_{i}=1, N P_{i}=1\right)$, the identification of indirect treatment effects relies on the assumption that it has the same expected value as the potential outcome in the absence of the program for non-poor households in control villages:

$$
\operatorname{ASSUMPTION}(1): E\left(Y_{0 i} \mid T_{i}=1, N P_{i}=1\right)=E\left(Y_{0 i} \mid T_{i}=0, N P_{i}=1\right)
$$

Under this assumption, the difference

$$
E\left(Y_{i} \mid T_{i}=1, N P_{i}=1\right)-E\left(Y_{i} \mid T_{i}=0, N P_{i}=1\right)
$$

identifies the ITE. Note that this is a slight modification of the standard assumption made for the identification of ATT effects.

Despite the randomization, assumption (1) would be violated if outcomes of non-poor households in control villages were indirectly affected by the program. However, if there are indirect program effects for non-poor households in both treatment and control villages, the sign of these effects is likely to be the same for the two groups. For example, suppose that the increase in school enrollment of treated children reduces child labor. This decrease in labor supply may results in higher employment and earnings for non-poor households in both treatment and control villages. Note, however, that the size of these effects is an inverse function of the degree of integration of the village economies. ${ }^{10}$ Going back to our example, the fall in relative labor supply may be small enough, compared to the total size of the labor market, to leave employment and earnings virtually unchanged. On the other hand, if the local economies are sufficiently isolated, then the indirect program effects are unlikely to extend to neighboring villages. In the presence of a violation of assumption (1) of the type described above, the difference $E\left(Y_{i} \mid T_{i}=1, N P_{i}=1\right)-E\left(Y_{i} \mid T_{i}=0, N P_{i}=1\right)$ is a lower bound to the ITE.

We obtain estimates of the ITEs (or of their bounds) from the following equation for non-

\footnotetext{
${ }^{9}$ We could rewrite the $I T E$ in its conditional version as $I T E=E\left(Y_{1 i}-Y_{0 i} \mid T_{i}=1, N P_{i}=1, X\right)$.

${ }^{10}$ Technically, what is needed is only integration of the product market in the presence of relatively large number of products traded with respect to factors (Mundell, 1966).
} 
poor households:

$$
Y_{i}=\alpha+\beta T_{i}+g\left(X_{i}\right)+u_{i}
$$

where the subscript $i$ refers to the $i-t h$ household, $Y_{i}$ is some outcome of interest (e.g. consumption). Under assumption (1), $\beta$ identifies the ITE. We add a set of conditioning variables, $X_{i}$, to increase the precision of the estimates. These are: poverty index, shock dummy, pre-program income and land, household size, dummies for head of household gender, age composition of the household, employment status, language (Spanish, indigenous language or both), and literacy, at the household level; village marginalization index, average number of shocks in the previous 6 months, number of households, number of treated households, geographic region dummies at the locality level. If we estimate (3) for poor households, $\beta$ identifies the ATT under the assumption that $E\left(Y_{0 i} \mid T_{i}=1\right)=E\left(Y_{0 i} \mid T_{i}=0\right){ }^{11}$

\section{Indirect Treatment Effect on consumption}

We now proceed to estimate ITEs for food and non-food consumption. We computed measures of monthly food and non-food expenditure per adult equivalent, using an equivalence scale estimated from these data. The Appendix provides further details on the creation of these variables.

Table 1: Average Monthly Food and Non-Food Consumption Levels per Adult Equivalent

\begin{tabular}{lcccccc}
\hline & \multicolumn{3}{c}{ Food consumption } & \multicolumn{3}{c}{ Non-food consumption } \\
& 1998 Oct. & 1999 May & 1999 Nov. & 1998 Oct. & 1999 May & 1999 Nov. \\
\hline NP control & 203.25 & 201.50 & 195.99 & 76.55 & 72.47 & 74.22 \\
& $(168.13)$ & $(197.00)$ & $(216.60)$ & $(87.92)$ & $(80.29)$ & $(80.86)$ \\
NP treatment & 198.41 & 220.87 & 212.27 & 74.54 & 77.51 & 71.08 \\
& $(160.43)$ & $(281.17)$ & $(263.19)$ & $(85.53)$ & $(90.13)$ & $(75.76)$ \\
P control & 137.47 & 144.59 & 139.39 & 34.58 & 36.91 & 37.24 \\
& $(103.10)$ & $(141.25)$ & $(116.05)$ & $(43.39)$ & $(41.99)$ & $(40.80)$ \\
P treatment & 151.16 & 168.52 & 168.59 & 36.09 & 42.59 & 41.97 \\
& $(122.17)$ & $(178.94)$ & $(191.25)$ & $(41.88)$ & $(46.02)$ & $(41.86)$ \\
\hline \hline
\end{tabular}

Note: Amounts are in pesos, the exchange rate was roughly 10 pesos per USD.

The means of food and non-food consumption in Table 1 show, as expected, that the nonpoor consume substantially more than the poor, even after treated poor receive the Progresa

\footnotetext{
${ }^{11}$ Actually, in this case $\beta$ identifies the average intent to treat effect, i.e. the effect of the treatment on eligible households irrespective of participation. However, in this case the difference between intent to treat and treatment on the treated is negligible, because about $97 \%$ of eligible households participate to the program. Therefore, we will continue referring to $\beta$ as ATT, when estimating (3) for poor households.
} 
transfers. However, the average non-poor household is clearly not very well-off, in absolute level: average food and non-food consumption for non-poor in control areas are about 20 and 7.5 U.S. dollars per adult equivalent per month. Lastly, consumption is higher in treated areas, especially for poor households, but also among non-poor ones (in May and November 1999 for food consumption, and in May 1999 only for non-food consumption).

We obtain estimates of the average Indirect Treatment Effect (ITE) for consumption by estimating (3) by OLS for each time period, using the logs of food and non-food consumption as dependent variables. We also report estimates of the ATTs for the poor (Table 2).

Table 2: Average effect of Progresa on log-food and non-food consumption

\begin{tabular}{ccccccc}
\hline \hline & \multicolumn{3}{c}{ Food consumption } & \multicolumn{3}{c}{ Non-food consumption } \\
& 1998 Oct. & 1999 May & 1999 Nov. & 1998 Oct. & 1999 May & 1999 Nov. \\
\hline \multirow{3}{*}{$\hat{T} E$} & -0.0213 & 0.0514 & 0.0669 & 0.0629 & 0.1384 & -0.0602 \\
& {$[0.0256]$} & {$[0.0257]^{* *}$} & {$[0.0211]^{* * *}$} & {$[0.0672]$} & {$[0.0655]^{* *}$} & {$[0.0623]$} \\
Obs. & 4602 & 3824 & 4257 & 4771 & 4259 & 4443 \\
$A \hat{T} T$ & 0.1033 & 0.1699 & 0.1892 & 0.0959 & 0.1675 & 0.1128 \\
& {$[0.0236]^{* * *}$} & {$[0.0219]^{* * *}$} & {$[0.0211]^{* * *}$} & {$[0.0651]$} & {$[0.0613]^{* * *}$} & {$[0.0540]^{* *}$} \\
Obs. & 10879 & 9605 & 10508 & 11484 & 10630 & 10856 \\
\hline \hline
\end{tabular}

Note: Standard errors in [brackets] clustered at the village level. ${ }^{* * *},{ }^{* *},{ }^{*}$ significant at $1,5,10 \%$ respectively.

The ITE is never significant in October 1998, a few months after the program began. Instead, food consumption is significantly higher in 1999 , by $5.1 \%$ in May and by $6.7 \%$ in November. This corresponds to about 10 and 13 pesos per adult equivalent respectively. Nonfood consumption is significantly different in May 1999 only, and it is higher by $13.8 \%$ in treatment areas, i.e. about 10 pesos per adult equivalent, while the effect is negative but not significant in November 1999. ${ }^{12}$ Thus, consumption increases overall by approximately 100 and 70 pesos per household per month in May and November 1999. ${ }^{13}$ Poor food and nonfood consumption, instead, increases in all three periods, consistent with the existing evidence (Skoufias et al., 1999); this impact is proportionally larger over time, although constant in absolute value in 1999, with an average monthly consumption increase of 30 pesos per adult equivalent.

The results above are robust to a variety of checks, as detailed in the Appendix. These include alternative ways of dealing with households who reported zero food and non-food consumption $(2.9 \%$ and $1.5 \%$, respectively), alternative treatment of households with extremely

\footnotetext{
${ }^{12}$ Total consumption for non-poor in treatment areas is $5.3 \%$ and $4.9 \%$ higher in May and November 1999 . Both differences are statistically significant. Results available upon request.

${ }^{13}$ The average adult equivalent household size is 5.0 and 5.3 in the two 1999 waves.
} 
large reported consumption levels, and alternative measures of food consumption. We also fail to detect any pre-program significant difference in food and non-food consumption between households in treatment and control villages.

\section{Why does Progresa increase non-poor consumption?}

We showed that Progresa has a positive spillover effect on non-poor consumption. This externality has multiple potential causes. First, the increased income of treated households, together with the surge in treated children's school attendance, and the decrease in child labor, may cause changes in the goods and labor markets, which could result in higher income for non-poor households. Second, non-poor households may receive additional aid, as we will explain below. Third, the increased liquidity in treatment villages may affect the local credit and insurance markets. Households may borrow more for investment or consumption purposes. ${ }^{14}$ Lastly, households may reduce their savings. A decrease in savings would be compatible with better insurance against risk, which lowers the need for self-insurance, or with a drop in interest rates caused by the increased liquidity. Note that the higher consumption may be financed through a drop in investment, although it is not clear why households would change their preferences in this way. We can summarize the above discussion using the following accounting identity:

$$
\Delta Y_{i}+\Delta L_{i}=\Delta C_{i}+\Delta S_{i}+\Delta I_{i}
$$

where $Y$ is income, $L$ are net loans and transfers, $C$ is consumption, $S$ are savings and $I$ investment for household $i$, and $\Delta$ is the indirect program effect for each outcome of interest. In the next sections we will consider these different channels individually, discussing and testing our hypotheses in greater details.

\subsection{Labor market effects}

The program may affect non-poor consumption levels through higher labor earnings, for example by increasing equilibrium wages or non-poor labor supply. These effects may occur if the move of poor children into schooling is large enough to decrease the overall labor supply. Their magnitude depends on the degree of integration of the local economy: the higher the integration, the smaller the program impact. For example, the potential drop in child labor caused by the increase in treated children's school attendance may increase labor earnings through higher

\footnotetext{
${ }^{14}$ The former effect would result in higher current consumption through higher current or permanent income.
} 
local wages, if treatment villages are economically isolated. While such an effect will be small if the village economies are sufficiently integrated.

Table 3: Cross Sectional Tobit Estimates of Program Effect on per Capita Monthly Household Labor Earnings

\begin{tabular}{ccccc}
\hline \hline & 1997 Sept. & 1998 Oct. & 1999 May & 1999 Nov. \\
\hline \multirow{T}{*}{ TीE } & -9.58 & 14.21 & -7.72 & 64.82 \\
& {$[46.99]$} & {$[39.57]$} & {$[44.63]$} & {$[49.49]$} \\
Obs. & 5095 & 4539 & 3806 & 4160 \\
$A \hat{T} T$ & -16.20 & 44.29 & -38.83 & 72.09 \\
& {$[21.83]$} & {$[18.87]^{* *}$} & {$[20.20]^{*}$} & {$[20.90]^{* * *}$} \\
Obs. & 12370 & 10818 & 9590 & 10426 \\
\hline \hline \multicolumn{5}{c}{ Note: ${ }^{* *},{ }^{* *},{ }^{*}$ significant at $1,5,10 \%}$.
\end{tabular}

We investigate this hypothesis by testing whether households in treatment and control villages earn a different labor income. We compute the household monthly labor earnings variable summing income from both primary and secondary occupations, using the reported wages (which may be daily, weekly, monthly or annual) and hours worked. Table 3 reports tobit cross-sectional estimates of differences in per capita monthly labor earnings, where the first column shows pre-program differences. We do not detect any statistically significant difference between non-poor households in treatment and control localities. The values of the point estimates is also low, compared with the consumption change, with the exception of a 64 peso earnings increase in November 1999 estimates, though not statistically different from zero. However, this difference becomes smaller once we consider also earnings from informal activities: we considered the effect on earnings from informal work activities such as the provision of transportation, cooking, sewing, repairs, carpentry, and various other paid services, and we found a small and negative program effect, although never significant. ${ }^{15}$ Lastly, we tested for differences in hours of work, which never change for the non-poor.Thus, we exclude that the increase in consumption is caused by labor-related indirect program effects.

As regards poor households, there is no clear trend in the program effect on labor income. The difference in earnings is significantly higher in October 1998 and November 1999, but lower in May 1999.

\footnotetext{
${ }^{15}$ We estimated these regressions also by OLS, since tobit estimates are inconsistent in the presence of heteroskedasticity. If we interpret the reported zero labor earnings as very low earnings, or as measurement error due e.g. to illness, then OLS estimates are consistent. The OLS estimates are never significant.
} 


\subsection{Goods market: effects on prices and sales}

It is possible that the higher expenditure induced by the Progresa transfers may increase goods prices. Again, this depends on the degree of integration of the goods market. If prices in treatment villages increase, and non-poor earnings from sales rise, the non-poor in treatment villages may use this extra income to consume more. In order to test this hypothesis, we first compare prices in treatment and control localities to see whether they are significantly different. ${ }^{16}$ To do so, we consider village prices by good and data wave. We provide details on the creation of the price variables in the Appendix, as well as estimates of the price differences between treatment and control villages. We noted that some prices differ before the program begins, in March 1998, hence we provide difference-in-difference (DD) estimates of the effect of the Program on village prices. This exercise is possible only for food prices, since there is no pre-program information on non-food prices. We find a small positive effect on 5 out of 36 food prices in October 1998, which we do not expect to increase the cost of the food basket substantially, because prices of staples such as rice, beans, corn, and chicken do not change. We find no food price change in the later waves, nor evidence of price changes from cross sectional variation, when we consider both food and non-food prices.

Table 4: Differences in monthly sales of agricultural products

\begin{tabular}{ccccccc}
\hline \hline & \multicolumn{5}{c}{1998 October } & \multicolumn{3}{c}{ Agriculture } \\
& Net sales & Costs & Gross sales & Net sales & Costs & Gross sales \\
\hline$I \hat{T} E$ & -18.21 & -8.87 & -19.12 & -35.95 & -17.86 & -41.25 \\
& {$[15.02]$} & {$[3.15]^{* * *}$} & {$[5.10]^{* * *}$} & {$[21.58]^{*}$} & {$[6.24]^{* * *}$} & {$[11.06]^{* * *}$} \\
Obs. & 4017 & 4100 & 4479 & 3469 & 3509 & 3763 \\
$A \hat{T} T$ & -3.72 & 3.19 & -1.11 & -3.90 & 1.67 & -3.51 \\
& {$[1.84]^{* *}$} & {$[0.75]^{* * *}$} & {$[0.53]^{* *}$} & {$[3.97]$} & {$[1.27]$} & {$[1.40]^{* *}$} \\
Obs. & 9458 & 9595 & 10696 & 8666 & 8759 & 8666 \\
& & & & Animals & & \\
& Net sales & Purchases & Gross sales & Net sales & Purchases & Gross sales \\
\hline ITTE & 1.99 & -0.07 & 0.72 & 0.17 & 0.02 & -0.59 \\
& {$[1.47]$} & {$[0.41]^{* * *}$} & {$[1.28]$} & {$[0.77]$} & {$[0.28]$} & {$[0.53]$} \\
Obs. & 4491 & 4541 & 4557 & 3736 & 3777 & 3779 \\
$A \hat{T} T$ & -0.17 & -0.03 & -0.03 & -0.09 & 0.18 & 0.15 \\
& {$[0.27]$} & {$[0.11]$} & {$[0.13]$} & {$[0.17]$} & {$[0.08]^{* *}$} & 0.10 \\
Obs. & 10640 & 9595 & 10760 & 9390 & 9493 & 9501 \\
\hline \hline
\end{tabular}

Note: differences in net sales estimated by OLS, with standard errors clustered at the village level.

Differences in gross sales and costs (purchases) estimated by tobit. ***, **, * significant at 1, 5, $10 \%$.

\footnotetext{
${ }^{16}$ Note that the higher consumption of treated households may increase local goods prices, resulting in higher nominal prices. However, this would not explain the observed increased consumption, since we use real prices in our measures of consumption.
} 
Even if prices do not differ between control and treatment villages, the non-poor in treated localities may earn a higher income than the non-poor in control villages by selling more goods to poor households. We test whether there is a significant difference in sales of agricultural products and of animals for poor and non-poor households in control and treatment villages. We compute net agricultural sales by subtracting production costs from the gross sales variable, and the net animal sales by subtracting the value of purchases from sales. No data are available in November 1999. Table 4 shows estimates of the ITEs and ATTs for these variables, at October 1998 prices. The agricultural ITEs are mainly negative and significant: households reduce production costs by 9 and 18 pesos, and sales by even more, namely by 20 and 40 pesos, resulting in lower net sales. While alternative explanations are possible, we suspect that part of this reduction in costs and sales is due to a reduction in the grains buffer stock, which are used to sow the land, and (or) as consumption of home produced goods. We will provide further evidence consistent with this hypothesis when estimating the program effects on savings. Irrespective of the determinants of this behavior, it is clear that the extra consumption is not financed through higher sales. There is also a small decrease in purchases of animals in 1998, together with a small and positive, yet imprecisely estimated, effect on net sales. Lastly, note the decrease in net sales for the poor, caused by a contemporaneous increase in costs and decrease in sales. We interpret this result as evidence that treated households increase both their agricultural production (and probably also their stock of grains) and their autoconsumption, producing more but selling less because a larger share of the harvest is consumed (or saved).

\subsection{Additional aid program recipience}

One additional possible cause for the higher non-poor consumption in treatment areas may be the higher relative supply of transfers from alternative welfare programs. This may occur for two reasons. The first one is that one of the aims of Progresa is to replace some of the numerous pre-existing welfare program into a single one (DIF, INI, Ninos de Solidaridad, Tortilla, and Liconsa). These programs range from the provision of food (Liconsa, Tortilla) to the assistance of specific sub-samples of the populations (children, in the case of Ninos de Solidaridad, and indigenous households for INI, the National Institute for Indigens). This may leave some agencies located in treatment villages with excess levels of aid (in cash or kind), which they may direct to households classified as non-poor. The second reason is a reduced need of treated households' additional welfare assistance because of Progresa. For example, if Progresa transfers help protect recipients against risk, they may be less in need of emergency assistance. This 
may be directed to some non-poor in treatment areas.

We test whether non-poor and poor households in treatment and control villages have significant different intakes of alternative welfare programs. We first create some aggregate measures of program receipt. These are the likelihood of participating in at least one alternative program; the number of programs the households participates to, for households who receive at least one alternative type of welfare; the total monetary transfers the households received in the previous month. We then test for differences in the likelihood of participating to individual programs. We present aggregate estimates of these differences in Table 5, while we report the difference in participation rates program by program in the Appendix. As expected, participation to alternative welfare programs is significantly lower for poor households in treatment communities in all post-program waves (nevertheless, they are still better off with Progresa). Thus, because of a reduction in recipients in treatment villages, it is possible that non-poor households may appropriate some of the resources previously targeted to poor households. Indeed, in May 1999 there is a 1.8 percentage point increase in the likelihood of receiving cash through Solidaridad, and a 0.7 percentage point increase in receipt of free milk for non-poor. However, these differences are very small. Moreover, there is no significant difference in the overall amount of monetary transfers received from cash programs, nor in participation rates to any other in-kind program in the two village groups.

Table 5: Cross sectional estimates of differences in participation to at least one alternative aid programs, in average number of programs benefits (for households who participate to at least one program), and in monetary receipt.

\begin{tabular}{lcccccccc}
\hline \hline & \multicolumn{4}{c}{ Non-poor } & \multicolumn{5}{c}{ Poor } \\
& 97 & 1998 Oct. & 1999 May & 1999 Nov. & 97 & 1998 Oct. & 1999 May & 1999 Nov. \\
\hline At least one & 0.033 & 0.013 & 0.043 & 0.013 & -0.001 & -0.089 & -0.132 & -0.078 \\
& {$[0.024]$} & {$[0.029]$} & {$[0.032]$} & {$[0.031]$} & {$[0.026]$} & {$[0.025]^{* * *}$} & {$[0.026]^{* * *}$} & {$[0.032]^{* *}$} \\
& 5260 & 4615 & 3822 & 4259 & 12482 & 10911 & 9606 & 10516 \\
How many if & 0.011 & -0.023 & 0 & -0.001 & 0.084 & -0.114 & -0.126 & -0.115 \\
& {$[0.038]$} & {$[0.028]$} & {$[0.028]$} & {$[0.030]$} & {$[0.058]$} & {$[0.019]^{* * *}$} & {$[0.021]^{* * *}$} & {$[0.022]^{* * *}$} \\
& 1293 & 2177 & 1661 & 1827 & 4356 & 4582 & 3396 & 3613 \\
Monetary & n.a. & 10.928 & 5.975 & -3.336 & n.a. & -26.036 & -19.178 & 1.133 \\
transfer & & {$[16.633]$} & {$[4.583]$} & {$[5.354]$} & & {$[6.078]^{* * *}$} & {$[2.321]^{* * *}$} & {$[1.747]$} \\
& & 4569 & 3784 & 4218 & & 10803 & 9513 & 10411 \\
\hline \hline
\end{tabular}

Note: We estimate the difference in the likelihood of participating to at least one program by probit, the difference in the number of programs participating to (if at least one) by OLS, and the total monetary receipt by tobit. Standard errors, between [brackets] clustered at the village level (apart from tobit). ***, **, * significant at 1, 5, $10 \%$.

In the Appendix we further consider the hypothesis that welfare receipt from alternative programs may have increased for non-poor in both treatment and control villages, and we provide evidence against it. In sum, we can exclude that the higher non-poor consumption in 
Progresa villages is primarily due to an increase in the receipt of welfare programs.

\subsection{Credit market}

The final transmission mechanism operates through the credit and insurance market. Financial market imperfections in developing countries are well documented in the literature: since formal insurance or credit institutions are almost absent, informal lending and risk-sharing mechanisms often arise, in the form of transfers and loans through social networks (see, for example, Townsend, 1995a; Fafchamps and Lund, 2003; and Munshi and Rosenzweig, 2005). In this sense, credit and insurance markets are in practice merged (see Udry, 1994, among others). As such, in the rest of the paper we consider them jointly, and often refer to them as "credit market". ${ }^{17}$ One advantage of these informal arrangements is their low likelihood of default, or of not reciprocating with transfers, because of the personal relationships between the agents involved, the high amount of available information, and the repeated nature of the interactions, which make exclusion from future transactions a costly punishment for defaulting.

When social networks and informal lending channels are important means to smooth consumption and insure against risk, even small liquidity injections into the network may have substantial spillover effects through increased loans and transfers. Note that the lender/donor here may be both a treated household, which can lend more money and transfer resources to non-treated neighbors because its income has increased, and a non-treated household, which may shift resources from poor households (less needy of help because they receive Progresa grants) to non-poor households within the same network. ${ }^{18,19}$ We believe that the program may have substantial indirect effects in the credit market for the following reasons: first, because most of the loans are informal: $70 \%$ of lenders are friends or relatives of the borrower (and a further $9 \%$ are local moneylenders). Second, because the scale of these informal networks is limited by their being based on personal relationships. Thus, the positive effects of a liquidity injection are shared by a limited number of households. ${ }^{20}$

We have information on receipt of loans in the previous six months, of transfers (monetary

\footnotetext{
${ }^{17}$ Our definition of credit market includes loans and transfers. In developing rural economies, transfers from family and friends may be considered as credit if the receiver reciprocates when the donor is in need.

${ }^{18}$ Program recipients are unlikely to leave the network and not share their income increase, if they are sufficiently forward-looking, because the Progresa grants may stop in November 1999, and will certainly almost entirely end after all the children complete 9 th grade.

${ }^{19}$ The direct effect on loans and transfers for poor households is ambiguous. Public transfers may crowd out private ones, as documented by Albarran and Attanasio (2002), and treated households may have less need to borrow. On the other hand, the higher liquidity in the village and the possibility of using the Progresa transfers as collateral to borrow against may cause an increase in loans to these households.

${ }^{20}$ Another possible explanation is that the liquidity injection lowers the informal interest rate, resulting in an increase of current consumption levels.
} 
and in kind) from family and friends during the previous month, but no information on the identity of lenders and donors, e.g. whether they are from poor or non-poor households. In order to understand the overall program indirect effect on the credit market, we need to observe these variables in all data waves. Unfortunately, this is possible only in October 1998, when very little money had been transferred to treated households. ${ }^{21}$ In the remaining waves, we observe loans in May 1999, and transfers in November 1999. We report means and standard deviations in Table 6 . Only about 12 percent of the non-poor and 8 percent of the poor receive any resources in October 1998. The average monthly receipt amounts to some 400 pesos for the non-poor, and to 260 pesos for the poor households. Interestingly, this pattern is common for all variables and semesters: a higher proportion of the non-poor receives resources, compared to the poor, and their average receipt is larger, both in treatment and in control villages. A possible explanation for loans may be that the non-poor have more assets, which can be used as collateral to borrow against. Instead, the larger transfer size may suggest that the non-poor belong to a wealthier network, where people transfer more resources. In any case, the larger transfer size suggests once more that the so-called non-poor households are indeed not very wealthy, otherwise they would not be in need of transfers from family and friends. Lastly, note that, for the non-poor, both the proportion of recipients and the size of the receipt are larger in treatment than in control areas. Instead, there appear to be no differences for poor households.

We want to test whether Progresa has an indirect impact on both the probability of receiving loans and transfers, and the amounts received, measured in pesos per month. For this purpose, we estimate versions of equation (3) by probit and tobit, using loans and transfers measures as dependent variables. Table 7 provides estimates of ITEs and ATTs. There are no significant program effects in 1998: the ITE point estimates are positive but very imprecisely estimated. This lack of significant effects is not surprising, as in October 1998 Progresa had only just started, and very little money had been transferred to the program recipients. Instead, these effects are positive and significant in 1999, when Progresa had been operating for at least one year. In May 1999, non-poor families in treated villages have a 1.5 percentage point higher chance of having a loan: this is $40 \%$ more than in control villages. They also borrow on average 3.8 more pesos per month, i.e. one third more than non-poor in control communities. This evidence is consistent with our conjecture that the program liquidity injection may relax a constraint on the lender side, enabling them to lend more. In November 1999, transfers to the non-poor are significantly higher by 6.6 pesos, or one third, in treatment

\footnotetext{
${ }^{21}$ We also observe migrant remittances in October 1998 and November 1999. We sum them to loans and transfers to compute our measure of total credit resources. We separately estimated indirect program effects on remittances, and found no significant effect. Results available upon request.
} 
Table 6: Credit Resources: mean, recipient proportion, and average amount obtained per recipient, by household type and semester

\begin{tabular}{|c|c|c|c|c|c|c|c|c|c|}
\hline & \multicolumn{3}{|c|}{1998 October } & \multicolumn{3}{|c|}{1999 May } & \multicolumn{3}{|c|}{1999 November } \\
\hline & Mean & $\%$ & Avg. receipt & Mean & $\%$ & Avg. receipt & Mean & $\%$ & Avg. receipt \\
\hline & \multicolumn{9}{|c|}{ Total credit resources: } \\
\hline \multirow[t]{2}{*}{ NP control } & 47.795 & 11.91 & 404.681 & & & & & & \\
\hline & {$[235.436]$} & & {$[571.121]$} & & & & & & \\
\hline \multirow[t]{2}{*}{ NP treatment } & 54.073 & 12.94 & 423.903 & & & & & & \\
\hline & {$[249.015]$} & & {$[574.522]$} & & & & & & \\
\hline \multirow[t]{2}{*}{ P control } & 21.651 & 8.44 & 259.939 & & & & & & \\
\hline & {$[125.693]$} & & {$[357.858]$} & & & & & & \\
\hline \multirow[t]{3}{*}{$\mathrm{P}$ treatment } & 22.201 & 8.59 & 260.398 & & & & & & \\
\hline & {$[125.184]$} & & {$[349.228]$} & & & & & & \\
\hline & \multicolumn{9}{|c|}{ Loans: } \\
\hline \multirow[t]{2}{*}{ NP control } & 8.218 & 2.84 & 289.264 & 11.165 & 3.71 & 301.057 & & & \\
\hline & {$[79.402]$} & & {$[378.541]$} & {$[105.302]$} & & {$[464.083]$} & & & \\
\hline \multirow[t]{2}{*}{ NP treatment } & 11.509 & 3.28 & 358.194 & 16.403 & 5.30 & 314.247 & & & \\
\hline & {$[116.847]$} & & {$[551.285]$} & {$[123.282]$} & & {$[446.186]$} & & & \\
\hline \multirow[t]{2}{*}{ P control } & 3.955 & 2.73 & 147.627 & 7.653 & 4.62 & 167.729 & & & \\
\hline & {$[37.238]$} & & [175.535] & {$[57.777]$} & & [215.808] & & & \\
\hline \multirow[t]{3}{*}{$\mathrm{P}$ treatment } & 4.012 & 2.75 & 147.324 & 7.257 & 4.30 & 170.541 & & & \\
\hline & [33.911] & & [145.677] & {$[61.744]$} & & {$[248.944]$} & & & \\
\hline & \multicolumn{9}{|c|}{ Monetary transfers from family and friends: } \\
\hline \multirow[t]{2}{*}{ NP control } & 29.203 & 3.89 & 751.666 & & & & 18.064 & 2.43 & 741.975 \\
\hline & {$[246.713]$} & & [1018.716] & & & & {$[246.090]$} & & [1413.340] \\
\hline \multirow[t]{2}{*}{ NP treatment } & 30.212 & 4.57 & 671.928 & & & & 26.991 & 3.74 & 737.183 \\
\hline & {$[223.084]$} & & {$[825.028]$} & & & & {$[201.382]$} & & {$[768.112]$} \\
\hline \multirow[t]{2}{*}{ P control } & 11.480 & 2.57 & 446.990 & & & & 3.596 & 1.33 & 274.826 \\
\hline & [110.974] & & {$[536.127]$} & & & & {$[43.101]$} & & {$[262.137]$} \\
\hline \multirow[t]{3}{*}{$\mathrm{P}$ treatment } & 10.198 & 2.61 & 397.255 & & & & 7.081 & 1.69 & 421.680 \\
\hline & [94.221] & & {$[439.463]$} & & & & {$[80.080]$} & & {$[457.063]$} \\
\hline & \multicolumn{9}{|c|}{ In-kind transfers from family and friends: } \\
\hline \multirow[t]{2}{*}{ NP control } & & 1.120 & & & & & & 1.623 & \\
\hline & & [1.054] & & & & & & [1.261] & \\
\hline \multirow[t]{2}{*}{ NP treatment } & & 1.921 & & & & & & 0.964 & \\
\hline & & {$[1.372]$} & & & & & & [9.743] & \\
\hline \multirow[t]{2}{*}{ P control } & & 1.492 & & & & & & 1.607 & \\
\hline & & {$[1.214]$} & & & & & & [1.255] & \\
\hline \multirow[t]{2}{*}{$\mathrm{P}$ treatment } & & 1.398 & & & & & & 1.033 & \\
\hline & & {$[1.171]$} & & & & & & [1.011] & \\
\hline
\end{tabular}

Note: Amounts are in pesos per month, the exchange rate was roughly 10 pesos per USD. The last percentile of positive values has been trimmed in the computation of the quantities but not for the proportions.

villages. These households have also a higher likelihood of receiving transfers, although the coefficient is imprecisely estimated. This evidence suggests that the liquidity injection caused by Progresa may benefit the non-poor through some resource redistribution. However, the proportion of non-poor households receiving in-kind transfers decreases significantly in November 1999. This suggests that there may be a shift in the composition of transfers (e.g. from food and clothing to money), again consistent with the higher liquidity brought by Progresa. ${ }^{22}$ To conclude, note that there is a significant decrease in both loans and in-kind transfers to treated households, and no effect on monetary transfers. Our results are robust to different treatments of the outliers and to the use of different estimators. ${ }^{23}$

\footnotetext{
${ }^{22}$ Unfortunately we do not have any information on the value of in-kind transfers, so we cannot compute the total value of transfers.

${ }^{23}$ We ran the above regressions on the entire sample, trimming the top percentile of the positive values, and dropping the four largest amounts, respectively. We ran all regressions by OLS. In all cases, the point estimates
} 
Table 7: Program Effects on Credit Resources

\begin{tabular}{|c|c|c|c|c|c|c|}
\hline & \multicolumn{2}{|c|}{1998 Oct. } & \multicolumn{2}{|c|}{1999 May. } & \multicolumn{2}{|c|}{1999 Nov. } \\
\hline & Probit & Tobit & Probit & Tobit & Probit & Tobit \\
\hline & \multicolumn{6}{|c|}{ Non-poor } \\
\hline & \multicolumn{6}{|c|}{ Total credit resources: } \\
\hline \multirow[t]{2}{*}{$I \hat{T} E$} & 0.0037 & 4.9357 & & & & \\
\hline & {$[0.0138]$} & {$[5.9083]$} & & & & \\
\hline \multirow[t]{2}{*}{ Obs. } & 4598 & 4595 & & & & \\
\hline & \multicolumn{6}{|c|}{ Loans: } \\
\hline \multirow[t]{2}{*}{$I \hat{T E}$} & 0.0073 & 4.0375 & 0.0151 & 3.7937 & & \\
\hline & {$[0.0064]$} & {$[3.5252]$} & {$[0.0076]^{*}$} & {$[2.0264]^{*}$} & & \\
\hline \multirow[t]{2}{*}{ Obs. } & 4598 & 4595 & 3671 & 3802 & & \\
\hline & \multicolumn{6}{|c|}{ Monetary transfers from family and friends: } \\
\hline \multirow[t]{2}{*}{$I \hat{T} E$} & 0.0007 & 1.561 & & & 0.0074 & 6.562 \\
\hline & {$[0.0057]$} & {$[3.5437]$} & & & {$[0.0048]$} & {$[3.720]^{*}$} \\
\hline \multirow[t]{2}{*}{ Obs. } & 4600 & 4525 & & & 4246 & 4194 \\
\hline & \multicolumn{6}{|c|}{ In-kind transfers from family and friends: } \\
\hline$\widehat{I T E}$ & 0.0038 & & & & -0.0059 & \\
\hline & {$[0.0029]$} & & & & {$[0.0036]^{*}$} & \\
\hline Obs. & 4479 & & & & 3973 & \\
\hline
\end{tabular}

\section{Poor}

\begin{tabular}{|c|c|c|c|c|c|}
\hline & \multicolumn{5}{|c|}{ Total credit resources: } \\
\hline \multirow[t]{2}{*}{$A \hat{T} T$} & 0.0024 & 0.5373 & & & \\
\hline & {$[0.0080]$} & {$[1.685]$} & & & \\
\hline \multirow[t]{2}{*}{ Obs. } & 10893 & 10885 & & & \\
\hline & \multicolumn{5}{|c|}{ Loans: } \\
\hline \multirow[t]{2}{*}{$A \hat{T} T$} & 0.0017 & 0.1068 & -0.0084 & -1.4556 & \\
\hline & {$[0.0042]$} & {$[0.5072]$} & {$[0.0061]$} & {$[0.6294]^{* * *}$} & \\
\hline \multirow[t]{2}{*}{ Obs. } & 10893 & 10889 & 9478 & 9569 & \\
\hline & \multicolumn{5}{|c|}{ Monetary transfers from family and friends: } \\
\hline \multirow[t]{2}{*}{$A \hat{T T}$} & -0.0007 & -0.5267 & & 0.0015 & 0.9958 \\
\hline & {$[0.0027]$} & {$[1.011]$} & & {$[0.0015]$} & {$[0.8763]$} \\
\hline \multirow[t]{2}{*}{ Obs. } & 10894 & 10741 & & 10500 & 10361 \\
\hline & \multicolumn{5}{|c|}{ In-kind transfers from family and friends: } \\
\hline \multirow[t]{2}{*}{$A \hat{T} T$} & -0.0009 & & & -0.0049 & \\
\hline & {$[0.0018]$} & & & {$[0.0019]^{* *}$} & \\
\hline Obs. & 10894 & & & 10500 & \\
\hline
\end{tabular}

Note: Top $1 \%$ of positive values is trimmed in the Tobit.

The usual controls are added in the regression.

Standard errors in [brackets] clustered at the village level

in the Probit regressions. ${ }^{* * *},{ }^{* *},{ }^{*}$ significant at 1, 5, $10 \%$ respectively. 
In sum, we found that both loans and family and friend transfers to the non-poor are significantly higher by one third in treatment villages in 1999. Assuming that the magnitudes of the effects are constant throughout the two 1999 semesters (since we observe loans in May and transfers in November), non-poor households receive on average an extra 10 pesos per month. This explains only part of the observed higher consumption, which amounts to about 100 and 70 pesos per household (in May and November 1999, respectively). ${ }^{24}$

\subsection{Savings and investments}

So far we have seen that the indirect program effect on consumption is not caused by increases in earnings and welfare receipt, and only partially caused by higher loans and transfers. The difference must be financed through a reduction in savings or investments, as shown in the accounting identity in (4).

Rural households' savings are primarily in the form of grains and livestock: fewer than one percent of non-poor households hold interest-bearing savings (although we do not explicitly observe their monetary value). We test for differences in the stock of grains and animals owned by the non-poor in treatment and control villages, comparing the tons of grains and number of animals owned. The change in stock may differ from the peso value of their net sales, which we showed in Table 4, if households start consuming part of their stock. This is exactly what we find: for grains, the peso value of the stock is lower for non-poor households in treatment villages, though imprecisely estimated. However, in May 1999 we find a significant effect on the likelihood of reducing the grain stock, which drops by 4.5 percentage points, and a 9 peso significant increase in consumption of own grains. We also find a decrease in livestock for the non-poor in treatment villages. In particular, the stock of chickens decreases significantly by 0.6 in 1998 (among households who own chickens), and the likelihood of owning pigs drops significantly by 3, 6, and 4 percentage points in October 1998, May 1999, and November 1999, respectively. This is not surprising, as chickens and pigs are the most widely held animals (by 61 and 34\% of households in October 1998, respectively). At the same time the number of animals, and both the quantity and the value of the stock of grains owned by the poor in

varied very little. We also found that the non-response rates, which vary between 0 and $5.4 \%$ for non-poor households, do not differ between treatment and control areas. This may have been an important issue, owing to the relatively small number of households reporting loans or transfers.

${ }^{24}$ Part of the consumption increase may be financed through a reduction in donations from non-poor households in treatment villages. This would be possible if, for example, the Progresa transfers to the poor were crowding out private transfers from the non-poor. However, the difference in resources donated from the non-poor in treatment and control villages is never statistically significant. Note that only a total of 56 non-poor households donated resources to family and friends in the October 1998 and November 1999 data. 
treatment villages have a substantial significant increase. ${ }^{25}$

These findings are consistent with both the empirical literature (e.g. Lim and Townsend (1998) and Udry (1995) show that households reduce their stock of grain in response to a shock) and with the predictions of models of incomplete risk sharing in which agents rely partially on self-insurance. These models predict that households hit by positive income shocks (the treated) increase their buffer stock, while households whose income has not changed (the non-poor) decrease savings because poor households' higher income improves insurance against risk. The absence of significant program effects on the peso value of grain stock and of net animal purchases suggests that part of the stock is now consumed (or used as productive input in the case of grains). At the same time, the positive program effect on loans and transfers suggests that households do share part of the risk.

Lastly, as regards investment, it is often difficult to separate it from savings and production costs (as in the case of purchase of fertilizers). While there is no conceptual reason why Progresa would indirectly decrease investment for the non-poor, one could interpret the drop in production costs in such a way.

\section{Consumption smoothing and insurance against risk: idiosyn- cratic shocks}

We have identified a positive indirect program effect on consumption for the non-poor, shown that this extra consumption is financed partly through increased loans and transfers, and partly by a reduction in both the stock of grains and animals, and the sales of agricultural products. We suspect that one important reason for this consumption increase and reduction in savings may be the improved insurance against risk caused by Progresa's liquidity injection into treatment communities. ${ }^{26}$ One way to test this hypothesis is to estimate separate indirect program effects on consumption, loans and transfers, and savings for households who have and have not been hit by a negative idiosyncratic shock. Consider non-poor households only. Some fraction of the non-poor is hit by idiosyncratic negative shocks, $S=1$, in both villages. If Progresa

\footnotetext{
${ }^{25}$ Results available upon request.

${ }^{26}$ Additional explanations for the observed increase in non-poor consumption are: first, the effect of better information on the importance of an adequate nutrition. All households in treatment villages were strongly encouraged to attend classes that covered health and nutrition topics. Such classes may have raised awareness on the importance of a nutritious diet, causing higher food expenditure. However, we have also seen an increase in non-food consumption. Second, the existence of "imitation" effects. Recent works by Lalive and Cattaneo (2005) and by Bobonis and Finan (2005) analyze peer effects on schooling decisions in Progresa communities. Both papers show that the school enrollment of ineligible children is a positive function of the enrollment of treated children. Analogously, imitation effects may also increase consumption. These additional causes for the increased consumption explain the reduction in savings, but not the observed increase in loans and transfers.
} 
improves insurance against risk, then we will observe all non-poor households in treatment villages increase their consumption through a mix of lower savings (because of the new access to loans and transfers if hit by a negative shock), and higher transfers and loans, compared to the non-poor in control villages. In addition, if shocks are random within village, we will see a larger increase in consumption and transfers for $S=1$ households than for $S=0$ households in treatment areas: if Progresa improves risk sharing in treatment villages, the indirect program effect on $S=1$ households consumption and loans and transfers will be proportionally higher than for households not hit by a shock. This occurs because households hit by a shock will need to smooth consumption more than households not hit by a shock, and they will partly do so by borrowing more (or by receiving more transfers). A clear prediction is that $S=0$ households should run down on their savings since the need for self-insurance is reduced by the availability of credit in the network. The double-difference effects on savings is instead ambiguous. For example, $S=1$ households may reduce savings equally in treatment and control villages, and finance the extra change in consumption through increased loans and transfers. ${ }^{27}$ In other words, a test of whether the ITEs on consumption, loans and transfers, and savings differ by shock between and within village type is an indirect test of the effect of the program on risk-sharing mechanisms.

Formally, we define two new parameters of interest: 28

$$
\begin{aligned}
& I T E^{S 0}=E\left(Y_{1 i}^{S 0}-Y_{0 i}^{S 0} \mid T_{i}=1, S_{i}=0, N P_{i}=1\right) \\
& I T E^{S 1}=E\left(Y_{1 i}^{S 1}-Y_{0 i}^{S 1} \mid T_{i}=1, S_{i}=1, N P_{i}=1\right)
\end{aligned}
$$

where $S_{i}$ is an idiosyncratic shock and the superscripts $S 1$ and $S 0$ stand for hit or not by the shock respectively. These parameters are the ITEs for households who have and have not been hit by a shock. We want to test the following hypotheses:

$$
\begin{aligned}
& I T E_{C}^{S 1}>I T E_{C}^{S 0}>0 \\
& I T E_{L}^{S 1}>I T E_{L}^{S 0}>0 \\
& I T E_{S}^{S 0}<0
\end{aligned}
$$

\footnotetext{
${ }^{27}$ Suppose that in the absence of Progresa all non-poor households not hit by a shock would consume 100, and households hit by a shock only 80 . With Progresa, non-poor households not hit by a shock increase consumption up to 110 through a mix of reduction in savings and higher transfers (each by 5). Households hit by an adverse shock, instead, further reduce their buffer stock, and receive even more assistance from their social network (each by 10), pushing their consumption from 80 to 100. In this case, the effect of Progresa on the change in transfers, savings, and consumption is higher for households hit by a negative shock.

${ }^{28}$ The structure of the identification problem could be also reformulated in the multiple treatment framework by defining 4 different treatments depending on the combination of $\mathrm{T}$ and $\mathrm{S}$.
} 
where the subscripts $C, L$ and $S$ refer to consumption, loans and transfers, and savings, respectively. We can identify the above parameters exploiting the randomization by assuming the following:

$\operatorname{ASSUMPTION}(2)$ :

$$
\begin{array}{ll}
2.1 & E\left(Y_{0 i}^{S 0} \mid T_{i}=1, S_{i}=0, N P_{i}=1\right)=E\left(Y_{0 i}^{S 0} \mid T_{i}=0, S_{i}=0, N P_{i}=1\right), \\
2.2 & E\left(Y_{0 i}^{S 1} \mid T_{i}=1, S_{i}=1, N P_{i}=1\right)=E\left(Y_{0 i}^{S 1} \mid T_{i}=0, S_{i}=1, N P_{i}=1\right) .
\end{array}
$$

Assumption 2 implies that shocks are random between treatment and control villages. This assumption seems realistic because the village randomization is made within homogeneous geographic regions. For example, if one region is arid, its treatment and control villages are equally likely to suffer from droughts. However, in order to compare $I T E^{S 1}$ and $I T E^{S 0}$, we also need to assume: first, that shocks are random within villages, conditional on household observable characteristics; second, that the extra liquidity injected by Progresa is sufficient to borrow both to offset the shock and for additional reasons; finally, that households are willing to lend.

We estimate the following equation both for non-poor and poor households:

$$
Y_{i}=\alpha+\beta_{1} T_{i}+\beta_{2} S_{i}+\beta_{3} T_{i} S_{i}+g\left(X_{i}\right)+u_{i}
$$

The parameters of interest in this second step are:

$$
\begin{aligned}
\beta_{1} & =E\left(Y_{i} \mid T_{i}=1, S_{i}=0\right)-E\left(Y_{i} \mid T_{i}=0, S_{i}=0\right) \\
\beta_{1}+\beta_{3} & =\left[E\left(Y_{i} \mid T_{i}=1, S_{i}=1\right)-E\left(Y_{i} \mid T_{i}=0, S_{i}=1\right)\right] \\
\beta_{3} & =\left[E\left(Y_{i} \mid T_{i}=1, S_{i}=1\right)-E\left(Y_{i} \mid T_{i}=0, S_{i}=1\right)\right] \\
& -\left[E\left(Y_{i} \mid T_{i}=1, S_{i}=0\right)-E\left(Y_{i} \mid T_{i}=0, S_{i}=0\right)\right] .
\end{aligned}
$$

Under the above assumptions, $\beta_{1}$ identifies $I T E^{S 0}$, i.e. the indirect program effect for households not hit by an idiosyncratic shock; $\beta_{1}+\beta_{3}$ identifies $I T E^{S 1}$, i.e. the effect for households hit by a shock; $\beta_{3}$ the difference between the two ITEs. The set of conditioning variables includes average shock intensity at the village level to control for aggregate shock, which is uninsurable (in the village), as well as all the variables discussed earlier. The household-specific shock 
dummy is then a measure of idiosyncratic shocks. Note that its coefficient is identified for villages where only a sub-set of households incurred a loss. We estimate (7) for both consumption and credit market outcomes.

In our data, we observe whether, in the six months preceding the interview, the household has been hit by any of the following types of natural disasters: drought, flood, frost, fire, plague, earthquake, and hurricane. This is our definition of shock. It is very specific, and it excludes other events that may cause income or wealth losses, such as illness or death of household members. We discuss this variable in greater detail in the Appendix; we provide evidence that there is a substantial within-village variation (Figure 2), consistent with Townsend (1994), who shows that natural phenomena - rainfall in his case - are not uniform even within very small villages; we also show that shocks hit households randomly. The average intensity of the shock at the village level is 39, 55 and 30\% in October 1998, and May and November 1999. This is a rough measure of how aggregate these shocks are. Note that the timing of the events and the way they are recorded in the data is quite important: the shocks must precede (or be contemporaneous to) the observed outcome of interest. This requirement is satisfied in our data: both shock and loans refer to the 6 months before the interview, while consumption, transfers, and savings data are provided for the previous week, month, and semester, respectively.

\subsection{Consumption by shock}

Table 8 provides means of food consumption by poverty status, village of residence, and shock. Consider food consumption, for example. While the means are not different in October 1998, consumption is higher in treatment villages irrespective of shock status in the two 1999 semesters. The comparison of consumption levels for non-poor households with and without the shock in the two villages types reveals the following: first, households hit by a shock in control villages tend to have the lowest average consumption levels. Second, consumption for households hit by a shock is higher in treatment than in control villages, but almost always lower than consumption for households in treatment villages who have not been hit by a shock. However, the standard deviations are very large. We repeat this comparison by regressing non-poor log-consumption on these four categories, as in equation 7, adding the usual set of conditioning variables to take account of possible differences in observable characteristics by group, and to improve the precision of the estimates.

We now test the hypotheses that indirect program effects are positive irrespective of shock status, and that the indirect program effect on consumption is higher for households who suffered a shock. The first hypothesis requires only the standard randomization assumption, 
Table 8: Average Monthly Food Consumption Levels per Adult Equivalent, by Shock

\begin{tabular}{lccc}
\hline \hline & \multicolumn{3}{c}{ Food consumption } \\
& 1998 Oct. & 1999 May & 1999 Nov. \\
\hline $\mathrm{S}=0$ & & & \\
NP control & 203.87 & 200.89 & 198.13 \\
& $(165.61)$ & $(179.71)$ & $(175.01)$ \\
NP treatment & 197.60 & 238.05 & 209.44 \\
& $(160.32)$ & $(342.09)$ & $(211.19)$ \\
$\mathrm{S}=1$ & & & \\
$\mathrm{NP}$ control & 202.39 & 201.94 & 191.68 \\
& $(171.63)$ & $(208.55)$ & $(282.50)$ \\
$\mathrm{NP}$ treatment & 199.62 & 208.42 & 217.77 \\
& $(160.67)$ & $(226.36)$ & $(342.58)$ \\
\hline $\mathrm{S}=0$ & & & \\
$\mathrm{P}$ control & 138.15 & 151.32 & 138.91 \\
& $(92.80)$ & $(123.51)$ & $(113.18)$ \\
$\mathrm{P}$ treatment & 152.02 & 170.27 & 168.48 \\
& $(131.40)$ & $(163.07)$ & $(207.15)$ \\
$\mathrm{S}=1$ & & & \\
$\mathrm{P}$ control & 136.59 & 140.13 & 140.54 \\
& $(115.05)$ & $(151.73)$ & $(122.74)$ \\
$\mathrm{P}$ treatment & 149.94 & 167.21 & 168.87 \\
& $(107.84)$ & $(189.97)$ & $(143.66)$ \\
\hline \hline
\end{tabular}

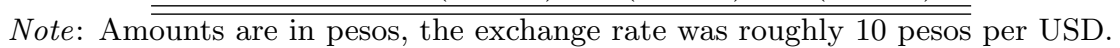

the second one also the other assumptions discussed in the previous section. The results are shown in Table 9. The estimates of the indirect program effects are positive and significant irrespective of shock status in both 1999 semesters. Food consumption in May and November 1999 increases significantly by $9.1 \%$ and $5.4 \%$ among households not hit by an idiosyncratic shock, and by $6.6 \%$ and $14.4 \%$ for households who were hit by a shock. Furthermore, while in May 1999 there is no statistical difference between their magnitude, in November 1999 the effect is 9 percentage points higher for households hit by a shock. The value of these changes in monthly pesos is 18.3 and 13.3 per adult equivalent (90 and 68 per household) for households without $(S=0)$ and with a shock $(S=1)$ in May 1999. The respective values for November 1999 are 10.7 and 27.7 per adult equivalent (or 55 and 152 per household). As regards poor households, the program effects are positive irrespective of shocks, they increase over time, as we saw in the previous consumption table, and never differ by shock status. The absolute value of these consumption changes is 20.3 (for $S=0$ households) and 24.3 monthly pesos (for $S=1$ households) per adult equivalent in May 1999, and 27.2 and 25.7 pesos in November 1999. There is a similar pattern for non-food consumption, although the positive trend is less marked. However, once we split non-poor households by shock, we do not find any significant 
indirect program effect for non-food consumption. ${ }^{29}$

Table 9: Effect of Progresa on Poor and Non-Poor Food Consumption, by Shock

\begin{tabular}{lcccccc}
\hline \hline & & Non-poor & & \multicolumn{3}{c}{ Poor } \\
& 1998 Oct. & 1999 May & 1999 Nov. & 1998 Oct. & 1999 May & 1999 Nov. \\
\hline$I T E^{S 0}$ & -0.0235 & 0.0911 & 0.0544 & 0.0972 & 0.1347 & 0.1958 \\
& {$[0.0303]$} & {$[0.0421]^{* *}$} & {$[0.0277]^{*}$} & {$[0.0243]^{* * *}$} & {$[0.0272]^{* * *}$} & {$[0.0228]^{* * *}$} \\
$I T E^{S 1}$ & 0.0168 & 0.066 & 0.1444 & 0.0991 & 0.1735 & 0.1832 \\
& {$[0.0360]$} & {$[0.0350]^{*}$} & {$[0.0364]^{* * *}$} & {$[0.0368]^{* * *}$} & {$[0.0285]^{* * *}$} & {$[0.0376]^{* * *}$} \\
\hline$I T \hat{E}^{S 1}-I T E^{S 0}$ & 0.0403 & -0.0251 & 0.0900 & -0.0019 & 0.0388 & -0.0126 \\
& {$[0.0422]$} & {$[0.0366]$} & {$[0.0431]^{* *}$} & {$[0.0140]$} & {$[0.0317]$} & {$[0.0309]$} \\
\hline Obs. & 4615 & 3825 & 4264 & 10911 & 9608 & 10517 \\
\hline \hline
\end{tabular}

Note: The usual controls are added in the regression. The standard errors in [brackets] are clustered at the village level. ${ }^{* * *},{ }^{* *},{ }^{*}$ significant $1,5,10 \%$ respectively.

\subsection{Credit market by shock}

We now proceed to estimate separate ITEs for households who have and have not been hit by a shock. Further, we test whether Progresa enables non-poor households hit by an idiosyncratic shock to borrow more (or receive more transfers) than households not hit by a shock. We perform such tests by estimating equation 7 for both the likelihood of receiving loans and transfers, and the amount received.

Table 10 reports means and proportion of credit resources by household and village type, and by shock occurrence. As we saw before, in general the indirect program effects on credit resources are larger over time. In addition, both the magnitude of these effects and the likelihood of receiving loans and transfers are larger for non-poor households hit by a shock, consistent with our expectations. A notable exception are monetary transfers in November 1999, when the effect for households hit by a shock is negative, and certainly lower than the effect for households not hit by a shock.

Table 11 provides estimates of the ITEs. In October 1998, households hit by an idiosyncratic shock are 2.6 percentage points more likely to receive loans or transfers if they live in treatment villages. Moreover, they borrow and receive about 22 pesos more per month. Instead, there is no significant effect for families not hit by a shock. It is striking that we detect these effects when Progresa had been implemented for a few months only. We interpret this fact as strong evidence that the program has an indirect effect on the credit market. We find the same type of effect for loans only, both in October 1998 and in May 1999. Once again, non-poor families who have been hit by a shock are about 2.5 percentage points more likely of

\footnotetext{
${ }^{29}$ Results available upon request.
} 
Table 10: Mean, Proportion, and Average Receipt of the Available Credit Resources, by Shock

\begin{tabular}{|c|c|c|c|c|c|c|c|c|c|}
\hline & \multicolumn{3}{|c|}{1998 Oct. } & \multicolumn{3}{|c|}{1999 May } & \multicolumn{3}{|c|}{ (1999 Nov. } \\
\hline & Mean & $\%$ & Avg. receipt & Mean & $\%$ & Avg. receipt & Mean & $\%$ & Avg. receipt \\
\hline & \multicolumn{9}{|c|}{ Total credit resources: } \\
\hline \multicolumn{10}{|l|}{$\mathrm{S}=0$} \\
\hline NP control & $\begin{array}{c}59.691 \\
{[278.566]}\end{array}$ & 12.61 & $\begin{array}{c}554.707 \\
{[885.931]}\end{array}$ & & & & & & \\
\hline NP treatment & $\begin{array}{c}52.273 \\
{[236.336]}\end{array}$ & 12.19 & $\begin{array}{c}538.312 \\
{[917.846]}\end{array}$ & & & & & & \\
\hline \multicolumn{10}{|l|}{$\mathrm{S}=1$} \\
\hline NP control & $\begin{array}{c}31.52 \\
{[157.179]}\end{array}$ & 10.95 & $\begin{array}{c}287.861 \\
{[391.637]}\end{array}$ & & & & & & \\
\hline NP treatment & $\begin{array}{c}56.791 \\
{[267.094]}\end{array}$ & 14.07 & $\begin{array}{c}551.742 \\
{[1413.64]}\end{array}$ & & & & & & \\
\hline \multicolumn{10}{|l|}{$\mathrm{S}=0$} \\
\hline P control & $\begin{array}{c}23.769 \\
{[133.549]}\end{array}$ & 8.17 & $\begin{array}{c}318.507 \\
{[446.005]}\end{array}$ & & & & & & \\
\hline $\mathrm{P}$ treatment & $\begin{array}{c}25.532 \\
{[140.043]}\end{array}$ & 8.73 & $\begin{array}{c}316.756 \\
{[449.479]}\end{array}$ & & & & & & \\
\hline \multicolumn{10}{|l|}{$\mathrm{S}=1$} \\
\hline P control & $\begin{array}{c}18.914 \\
{[114.728]}\end{array}$ & 8.78 & $\begin{array}{c}277.192 \\
{[540.304]}\end{array}$ & & & & & & \\
\hline \multirow[t]{2}{*}{$\mathrm{P}$ treatment } & $\begin{array}{c}17.509 \\
{[100.426]}\end{array}$ & 8.4 & $\begin{array}{c}235.682 \\
{[404.897]}\end{array}$ & & & & & & \\
\hline & \multicolumn{9}{|c|}{ Loans: } \\
\hline \multicolumn{10}{|l|}{$\mathrm{S}=0$} \\
\hline NP control & $\begin{array}{c}10.613 \\
{[97.103]}\end{array}$ & 3.08 & $\begin{array}{l}344.271 \\
{[443.67]}\end{array}$ & $\begin{array}{c}16.295 \\
{[140.126]}\end{array}$ & 4.63 & $\begin{array}{c}352.318 \\
{[562.472]}\end{array}$ & & & \\
\hline NP treatment & $\begin{array}{c}7.994 \\
{[84.879]}\end{array}$ & 2.34 & $\begin{array}{c}340.95 \\
{[445.567]}\end{array}$ & $\begin{array}{c}11.912 \\
{[84.185]}\end{array}$ & 4.53 & $\begin{array}{c}386.82 \\
{[839.32]}\end{array}$ & & & \\
\hline \multicolumn{10}{|l|}{$\mathrm{S}=1$} \\
\hline NP control & $\begin{array}{c}4.935 \\
{[44.821]}\end{array}$ & 2.51 & $\begin{array}{c}196.623 \\
{[211.166]}\end{array}$ & $\begin{array}{c}7.522 \\
{[70.734]}\end{array}$ & 3.06 & $\begin{array}{c}245.998 \\
{[329.858]}\end{array}$ & & & \\
\hline NP treatment & $\begin{array}{c}{[6.836} \\
16.82 .945]\end{array}$ & 4.70 & $\begin{array}{c}804.233 \\
{[2289.049]}\end{array}$ & $\begin{array}{c}19.636 \\
{[144.983]}\end{array}$ & 5.86 & $\begin{array}{c}392.704 \\
{[692.395]}\end{array}$ & & & \\
\hline $\mathrm{S}=0$ & & & & & & & & & \\
\hline P control & $\begin{array}{c}2.919 \\
{[29.285]}\end{array}$ & 2.35 & $\begin{array}{c}166.348 \\
{[244.262]}\end{array}$ & $\begin{array}{c}8.299 \\
{[57.572]}\end{array}$ & 4.55 & $\begin{array}{c}285.46 \\
{[625.651]}\end{array}$ & & & \\
\hline $\mathrm{P}$ treatment & $\begin{array}{c}4.848 \\
{[40.215]}\end{array}$ & 2.74 & $\begin{array}{l}176.758 \\
{[169.78]}\end{array}$ & $\begin{array}{c}9.772 \\
{[73.982]}\end{array}$ & 4.58 & $\begin{array}{l}249.653 \\
{[371.46]}\end{array}$ & & & \\
\hline $\mathrm{S}=1$ & & & & & & & & & \\
\hline P control & $\begin{array}{c}5.294 \\
{[45.471]}\end{array}$ & 3.21 & $\begin{array}{c}165.014 \\
{[196.799]}\end{array}$ & $\begin{array}{c}7.227 \\
{[57.921]}\end{array}$ & 4.66 & $\begin{array}{c}155.239 \\
{[222.573]}\end{array}$ & & & \\
\hline $\mathrm{P}$ treatment & $\begin{array}{c}2.834 \\
{[22.12]}\end{array}$ & 2.76 & $\begin{array}{c}145.15 \\
{[264.066]}\end{array}$ & $\begin{array}{c}5.376 \\
{[50.628]}\end{array}$ & 4.10 & $\begin{array}{c}168.005 \\
{[476.358]}\end{array}$ & & & \\
\hline & & & & netary tran & fers fro & family and $\mathrm{fr}$ & nds: & & \\
\hline $\mathrm{S}=0$ & & & & & & & & & \\
\hline NP control & $\begin{array}{c}40.373 \\
{[307.972]}\end{array}$ & 4.46 & $\begin{array}{c}905.761 \\
{[1171.238]}\end{array}$ & & & & $\begin{array}{c}12.179 \\
{[117.691]}\end{array}$ & 2.14 & $\begin{array}{c}569.854 \\
{[586.588]}\end{array}$ \\
\hline NP treatment & $\begin{array}{c}33.441 \\
{[254.179]}\end{array}$ & 4.97 & $\begin{array}{c}816.626 \\
{[1240.642]}\end{array}$ & & & & $\begin{array}{c}32.36 \\
{[229.979]}\end{array}$ & 3.97 & $\begin{array}{c}1176.285 \\
{[2134.937]}\end{array}$ \\
\hline$S=1$ & & & & & & & & & \\
\hline $\mathrm{NP}$ control & $\begin{array}{c}13.71 \\
{[115.6941}\end{array}$ & 3.09 & $\begin{array}{c}443.478 \\
{[502.789]}\end{array}$ & & & & 29.848 & 2.43 & $\begin{array}{c}984.971 \\
02095.81\end{array}$ \\
\hline NP treatment & {$\left[\begin{array}{c}115.694] \\
25.37\end{array}\right.$} & 3.96 & $\begin{array}{c}{[502.789]} \\
641.159\end{array}$ & & & & $\begin{array}{c}{[392.487]} \\
16.428\end{array}$ & 3.74 & $\begin{array}{c}{[2095.718]} \\
502.241\end{array}$ \\
\hline $\mathrm{S}=0$ & {$[165.848]$} & & {$[553.774]$} & & & & {$[127.094]$} & & {$[508.405]$} \\
\hline P control & $\begin{array}{c}12.603 \\
{[113.466]}\end{array}$ & 2.95 & $\begin{array}{c}426.823 \\
{[512.747]}\end{array}$ & & & & $\begin{array}{c}2.870 \\
{[38.251]}\end{array}$ & 1.17 & $\begin{array}{c}504.882 \\
{[1476.105]}\end{array}$ \\
\hline $\mathrm{P}$ treatment & $\begin{array}{c}{[113.400]} \\
12.986 \\
{[114.76]}\end{array}$ & 2.73 & $\begin{array}{c}531.477 \\
{[614.372]}\end{array}$ & & & & $\begin{array}{c}7.614 \\
{[86.942]}\end{array}$ & 1.74 & $\begin{array}{c}546.007 \\
{[1038.744]}\end{array}$ \\
\hline $\mathrm{S}=1$ & & & & & & & & & \\
\hline P control & 10.034 & 2.07 & 484.054 & & & & $\begin{array}{c}5.345 \\
{[52.969]}\end{array}$ & 1.72 & 311.628 \\
\hline $\mathrm{P}$ treatment & $\begin{array}{c}6.274 \\
{[53.035]}\end{array}$ & 2.44 & $\begin{array}{c}317.059 \\
{[517.004]}\end{array}$ & & & & $\begin{array}{c}5.737 \\
{[59.312]}\end{array}$ & 1.59 & $\begin{array}{l}360.816 \\
{[310.396]}\end{array}$ \\
\hline & & & & ind transfe & from & mily and frienc & $(\%):$ & & \\
\hline $\mathrm{S}=0$ & & & & & & & & & \\
\hline NP control & & 0.77 & & & & & & 1.75 & \\
\hline $\mathrm{NP}$ treatment & & 2.28 & & & & & & 0.70 & \\
\hline NP control & & 1.45 & & & & & & 1.06 & \\
\hline NP treatment & & 1.68 & & & & & & 1.49 & \\
\hline $\mathrm{S}=0$ & & & & & & & & & \\
\hline P control & & 1.45 & & & & & & 1.78 & \\
\hline $\mathrm{P}$ treatment & & 1.48 & & & & & & 0.96 & \\
\hline$S=1$ & & & & & & & & & \\
\hline P control & & 1.27 & & & & & & 1.17 & \\
\hline $\mathrm{P}$ treatment & & 1.27 & & & & & & 1.29 & \\
\hline
\end{tabular}


Table 11: Effect of Progresa on Credit for the Non-poor, by Shock

\begin{tabular}{|c|c|c|c|c|c|c|}
\hline & \multicolumn{2}{|c|}{1998 Oct. } & \multicolumn{2}{|c|}{1999 May. } & \multicolumn{2}{|c|}{1999 Nov. } \\
\hline & Probit & Tobit & Probit & Tobit & Probit & Tobit \\
\hline & \multicolumn{6}{|c|}{ Total credit resources: } \\
\hline$I T \hat{E}^{S 0}$ & $\begin{array}{l}-0.0117 \\
{[0.0173]}\end{array}$ & $\begin{array}{c}-5.679 \\
{[7.3795]}\end{array}$ & & & & \\
\hline$I T \hat{E}^{S 1}$ & $\begin{array}{c}0.0263 \\
{[0.0195]}\end{array}$ & $\begin{array}{c}22.039 \\
{[8.9567]^{* *}}\end{array}$ & & & & \\
\hline$I T \hat{E}^{S 1}-I T \hat{E}^{S 0}$ & $\begin{array}{c}0.038 \\
{[0.0233]^{*}}\end{array}$ & $\begin{array}{c}27.718 \\
{[11.9991]^{* *}}\end{array}$ & & & & \\
\hline \multirow[t]{2}{*}{ Obs. } & 4598 & 4595 & & & & \\
\hline & \multicolumn{6}{|c|}{ Loans: } \\
\hline$I T \hat{E}^{S 0}$ & $\begin{array}{l}-0.0057 \\
{[0.0079]}\end{array}$ & $\begin{array}{l}-4.2357 \\
{[4.3411]}\end{array}$ & $\begin{array}{c}0.0063 \\
{[0.0127]}\end{array}$ & $\begin{array}{l}-0.2219 \\
{[2.7923]}\end{array}$ & & \\
\hline$I T \hat{E}^{S 1}$ & $\begin{array}{c}0.0264 \\
{[0.011]^{* * *}}\end{array}$ & $\begin{array}{c}16.6777 \\
{[4.976]^{* * *}}\end{array}$ & $\begin{array}{c}0.0249 \\
{[0.0139]^{* *}}\end{array}$ & $\begin{array}{c}7.5166 \\
{[2.6014]^{* * *}}\end{array}$ & & \\
\hline$I T \hat{E}^{S 1}-I T \hat{E}^{S 0}$ & $\begin{array}{c}0.0321 \\
{[0.0109]^{* * *}}\end{array}$ & $\begin{array}{c}20.9134 \\
{[7.5773]^{* * *}}\end{array}$ & $\begin{array}{c}0.0186 \\
{[0.0163]}\end{array}$ & $\begin{array}{c}7.7385 \\
{[4.1162]^{*}}\end{array}$ & & \\
\hline Obs. & 4598 & 4595 & 3671 & 3802 & & \\
\hline & \multicolumn{6}{|c|}{ Monetary transfers from family and friends: } \\
\hline$I T E^{S 0}$ & $\begin{array}{c}0.0013 \\
{[0.0069]}\end{array}$ & $\begin{array}{c}0.9502 \\
{[20.8995]}\end{array}$ & & & $\begin{array}{c}0.0125 \\
{[0.0072]^{*}}\end{array}$ & $\begin{array}{c}11.8295 \\
{[4.3498]^{* * *}}\end{array}$ \\
\hline$I T \hat{E}^{S 1}$ & $\begin{array}{l}-0.0004 \\
{[0.0076]}\end{array}$ & $\begin{array}{c}4.3990 \\
{[5.7945]}\end{array}$ & & & $\begin{array}{l}-0.0009 \\
{[0.0074]}\end{array}$ & $\begin{array}{l}-1.9762 \\
{[5.8670]}\end{array}$ \\
\hline$I T \hat{E}^{S 1}-I T \hat{E}^{S 0}$ & $\begin{array}{l}-0.0017 \\
{[0.0089]}\end{array}$ & $\begin{array}{c}3.4488 \\
{[6.0505]}\end{array}$ & & & $\begin{array}{l}-0.0134 \\
{[0.0098]}\end{array}$ & $\begin{array}{l}-13.8057 \\
{[7.5441]^{*}}\end{array}$ \\
\hline Obs. & 4600 & 4525 & & & 4246 & 4194 \\
\hline & \multicolumn{6}{|c|}{ In-kind transfers from family and friends: } \\
\hline$I T \hat{E}^{S 0}$ & $\begin{array}{c}0.0102 \\
{[0.0052]^{* *}}\end{array}$ & & & & $\begin{array}{c}-0.0078 \\
{[0.0033]^{* *}}\end{array}$ & \\
\hline$I T \hat{E}^{S 1}$ & $\begin{array}{l}-0.0027 \\
{[0.0044]}\end{array}$ & & & & $\begin{array}{c}0.0083 \\
{[0.0070]}\end{array}$ & \\
\hline$I T \hat{E}^{S 1}-I T \hat{E}^{S 0}$ & $\begin{array}{c}-0.0129 \\
{[0.0063]^{* *}}\end{array}$ & & & & $\begin{array}{l}0.0161 \\
{[0.09]^{*}}\end{array}$ & \\
\hline Obs. & 4479 & & & & 3973 & \\
\hline
\end{tabular}

Note: Top 1\% of positive values is trimmed in the Tobit. The usual controls are added in the regression. The standard errors in [brackets] are clustered at the village level in the Probit regressions.

$* * *, * *, *$ significant at $1,5,10 \%$ respectively. 
borrowing money, and borrow 16.5 and 7.5 pesos more than their counterfactual in 1998 and 1999. These results are consistent with our hypothesis that Progresa may enable households to insure against risk by borrowing more: the estimated ITEs are larger for households hit by a shock. Interestingly, the effects for monetary transfers vary over time. In October 1998 the average transfer size is positive for both groups, and larger for households hit by a shock, but these effects are imprecisely estimated. In November 1999, instead, we find that the effect of the program on transfers is positive and significant, and averages about 12 pesos per month, only for households not hit by a shock. One possible explanation for this counterintuitive finding may be that higher loans are crowding transfers out. Alternatively, this finding is consistent with the hypothesis that transfers occur between "closer" individuals than the parties involved in loans. The former group's geographic, as well as social higher proximity, results into shocks being positively correlated. Unfortunately, we do not have data on loans for the same semester, nor complete data on social networks, hence we cannot draw any conclusion regarding either effects. However, note that the finding that risk is shared through informal loans, rather than through transfers, is consistent with the evidence provided by Fafchamps and Lund (2003) for the Philippines. Lastly, note that there is no clear pattern for the likelihood of receiving in-kind transfers: the difference in ITEs is negative in October 1998, and positive in November 1999. The magnitude of this difference is between 1.2 and 1.6 percentage points. ${ }^{30}$

In sum, the results presented in this section are consistent with our hypothesis of better risk-sharing through a more liquid credit market. Non-poor households in Progresa villages indirectly benefit from the program by receiving more credit resources when hit by a shock.

\subsection{Savings}

We finally test for indirect program effect on savings by shock. Our prediction is that the ITE for households not hit by a shock is negative, while the effect on savings for $S=1$ households is not clear. We test for changes in the stock of corn and beans, staples of the Mexican diet and easily storable commodities. The prediction is confirmed by the data: while there is no change in the stock of beans, $S=0$ households reduce their stock of corn through a significant increase in the value of home consumption of about 10 pesos per month in May 1999. In the same semester, their likelihood of depleting agricultural stock is significantly higher by 8 percentage points in treated communities. Instead, there is no clear pattern for households hit by a shock:

\footnotetext{
${ }^{30}$ One potential limitation of this exercise is the small sample size: in each semester, there are no more than 500 non-poor families receiving transfers or borrowing money, which we compare after dividing them into four groups based on village type and shock occurrence. This number is even smaller when we consider loans and transfers separately.
} 
we observe a shift in production from sugar cane to corn, and a significant increase in home consumption of the same magnitude as $S=0$ households, but their total grain stock appears to be unchanged. As regards livestock, we found evidence of a significant depletion for both types of households, especially of chickens and pigs. The change in stock does not differ by shock. ${ }^{31}$

Overall, the presented evidence is consistent with the conjecture that non-poor households in treatment areas may indirectly benefit from Progresa by being able to consume more because of improvements in the credit and insurance markets.

\section{Conclusions}

Using the unique design of the randomized data for the evaluation of Progresa, we show that non-eligible households who live in treatment villages benefit indirectly from the program by increasing their consumption level. We further show that the consumption increase occurs through changes in the credit and insurance markets, which enable households to borrow more and to receive more transfers, permitting them to reduce their savings. We conclude that this class of aid programs improves consumption smoothing for non-treated households living in treatment areas, consistent with the findings that, though the program increases consumption and loans, and decreases savings for all non-poor households in treatment villages, the effects on consumption and loans are larger for families hit by a negative idiosyncratic shock. These results are consistent with our knowledge of the credit and insurance markets in developing countries, which operate through social networks. A positive income shock to any member is likely to benefit the whole network.

Our findings are interesting from several perspectives. They show how households in developing countries deal with credit market imperfections, and how a liquidity increase may have beneficial indirect effects on the local community at large, including households whose current income does not change. Thus, this class of aid policies has important spillover effects which should not be neglected when evaluating the impact of the program.

In addition, this exercise is a striking example of circumstances in which the SUTVA, a key identifying assumption normally used in the program evaluation literature, fails. This assumption is non-testable when the experimental design consists of one treatment and one control group. However, its likelihood of being violated may be a function of observable characteristics of the programs and of the local economies where it operates. We suspect that the charac-

\footnotetext{
${ }^{31}$ However, the effect on the value of net sales is negative and significant only for $S=1$ households, a reduction of 32 pesos in May 1999, and does not change for $S=0$ households. It is possible that this latter group consumes part of its livestock, rather than selling it.
} 
teristics of Progresa which cause a significant indirect program effect are that this program 1) targets a large proportion of the population of a local economy; 2) has generously-sized transfers; 3) relaxes some existing binding constraints (lending constraints in this case); 4) operates in areas where the treated and non-treated subjects are sufficiently "close" (from an economic, geographic, or social perspective); and 5) has been ongoing for a sufficient amount of time. Analyzing similar features of different programs may provide guidelines on the robustness of the SUTVA.

\section{References}

\section{References}

[1] Albarran, Pedro and Orazio Attanasio. 2002. "Do Public Transfers Crowd out Private Transfers? Evidence from a Randomized Experiment in Mexico". WIDER discussion paper $2002 / 6$.

[2] Attanasio, O., (2000), "Consumption", Handbook of Macroeconomics, Volume 1B, Taylor, J. and M. Woodford, eds., Amsterdam: Elsevier Science.

[3] Banerjee, A., (2004), "Inequality and Investment", mimeo, MIT.

[4] Banerjee, A., Duflo, E. and Munshi, K., (2003), "The (Mis)Allocation of Capital", Journal of the European Economic Association, 1(2-3): 484-494.

[5] Berhman, J., and Todd, P. (1999), "Randomness in the Experimental Sample of Progresa (Education, Health, and Nutrition Program)", International Food Policy Research Institute, Washington, D.C.

[6] Blundell, R., Costa-Dias, M., Meghir, C. and van Reenen, J., (2004), "Evaluating the Employment Impact of a Mandatory Job Search Program", Journal of the European Economic Association, 2(4): 569-606.

[7] Bobonis, G. and Finan, F. (2005), "Endogenous Social Interaction Effects in School Participation in Rural Mexico", mimeo, University of California Berkeley.

[8] Deaton, A. (1991), "Saving and Liquidity Constraints", Econometrica, 59(5): 1221-48.

[9] Deaton, A. (1997), "The Analysis of Household Survey Data", Baltimore: Johns Hopkins University Press. 
[10] Di Maro, V. (2004), "Evaluation of the Impact of Progresa on Nutrition: Theory, Econometric Methods and an Approach to Deriving Individual Welfare Findings from Household Data", mimeo, University College London.

[11] Duflo, E. and Saez, E. (2002), "The Role of Information and Social Interactions in Retirement Plan Decisions: Evidence from a Randomized Experiment," unpublished working paper, MIT and University of California, Berkeley.

[12] Fafchamps, M. and Lund, S., (2003), "Risk-sharing Networks in Rural Philippines", Journal of Development Economics, 71(2): 261-87.

[13] Heckman, J., Lalonde, R. and Smith, J., (1999), "The Economics and Econometrics of Active Labor Market Programs", Handbook of Labor Economics, Volume 3, Ashenfelter, A. and D. Card, eds., Amsterdam: Elsevier Science.

[14] Heckman, J., Lochner, L. and Taber, C., (1998), "Explaining Rising Wage Inequality: Explorations with a Dynamic General Equilibrium Model of Labor Earnings with Heterogeneous Agents", National Bureau of Economic Research, Inc, NBER Working Papers: 6384 .

[15] Heckman, J. and Smith, J., (2004), "The Determinants of Participation in a Social Program: Evidence from a Prototypical Job Training Program", Journal of Labor Economics, 22(4): 243-298.

[16] Hoddinott, J., Skoufias, E., and Washburn, R. (2000) "The Impact of Progresa on Consumption: a Final Report". International Food Policy Research Institute, Washington, D.C.

[17] Hotz, J., Imbens, G. and Klerman, J., (2000), "The Long-Term Gains from GAIN: A ReAnalysis of the Impacts of the California GAIN Program", National Bureau of Economic Research, Inc, NBER Working Papers: 8007.

[18] Katz, L., J. Kling, and J. Liebman (2001): "Moving to Opportunity in Boston: Early Results of a Randomized Mobility Experiment," Quarterly Journal of Economics, 116: $607-54$.

[19] Lalive, R. and Cattaneo, A., (2005), "Social Interactions and Schooling Decisions", Mimeo, University of Zurich. 
[20] Lim, Y. and Townsend, R. (1998), "General Equilibrium Models of Financial Systems: Theory and Measurement in Village Economies", Review of Economic Dynamics, 1(1): 59-118.

[21] Lise, J., Seitz, S. and Smith, J., (2005), "Evaluating search and matching models using experimental data", mimeo, University of Michigan.

[22] Lise, J., Seitz, S. and Smith, J., (2005), "Equilibrium Policy Experiments and the Evaluation of Social Programs", mimeo, University of Michigan.

[23] Miguel, E. and Kremer, M. (2004), "Worms: identifying impacts on education and health in the presence of treatment externalities," Econometrica, 72(1): 159-217.

[24] Mundell, R., (1968), "International Economics", New York: Macmillan, 1968, pp. 85-99.

[25] Munshi, K. and Rosenzweig, M., (2005), "Why is Mobility in India so Low? Social Insurance, Inequality, and Growth", CID Working Paper No. 121, Harvard.

[26] Parker, S. and Skoufias, E., (2000), "Final Report: The Impact of PROGRESA on Work, Leisure, and Time Allocation", International Food Policy Research Institute, Washington.

[27] Philipson, T, (2000), "External Treatment Effects and Program Implementation Bias", National Bureau of Economic Research, Inc, NBER Technical Working Papers: 250.

[28] Rosenzweig, M. (1988a), "Risk, Private Information, and the Family," American Economic Review, 78(2): 245-50.

[29] Rosenzweig, M. (1988b), "Risk, Implicit Contracts and the Family in Rural Areas of LowIncome Countries", The Economic Journal, 98(393): 1148-70.

[30] Rubin, D., (1980), "Discussion of Randomization Analysis of Experimental Data: The Fisher Randomization Test by D.Basu", Journal of the American Statistical Association, 75: 591-93.

[31] Rubin, D, (1986), "Which ifs have causal answers? Discussion of Hollands Statistics and causal inference", Journal of the American Statistical Association, 81: 961-62.

[32] Rubin, D., (2005), "Causal Inference Using Potential Outcomes: Design, Modeling, Decisions", Journal of the American Statistical Association, 100(469): 322-31.

[33] Sacerdote, B. (2001), "Peer Effects with Random Assignment: Results for Dartmouth Roommates," Quarterly Journal of Economics, 116: 681-704. 
[34] Schultz, P., (2001), "School Subsidies for the Poor: Evaluating the Mexican PROGRESA Poverty Program", forthcoming in Journal of Development Economics.

[35] Skoufias, E., Davis, B. and Behrman, J., (1999a), "Final Report: An Evaluation of the Selection of Beneficiary Households in the Education, Health, and Nutrition Program (PROGRESA) of Mexico", International Food Policy Research Institute, Washington, D.C.

[36] Skoufias, E., Davis, B. and de la Vega, S., (1999b), "An Addendum to the Final Report: An Evaluation of the Selection of Beneficiary Households in the Education, Health, and Nutrition Program (PROGRESA) of Mexico. Targeting the Poor in Mexico: Evaluation of the Selection of Beneficiary Households into PROGRESA", International Food Policy Research Institute, Washington, D.C.

[37] Townsend, R., (1994), "Risk and Insurance in Village India", Econometrica, 62(3): 539591.

[38] Townsend, R., (1995a), "Consumption Insurance: An Evaluation of Risk-Bearing Systems in Low-Income Economies", The Journal of Economic Perspectives, 9(3): 83-102.

[39] Townsend, R., (1995b), "Financial Systems in Northern Thai Villages," The Quarterly Journal of Economics, 110(4): 1011-46.

[40] Udry, C. (1994), "Risk and Insurance in a Rural Credit Market: An Empirical Investigation in Northern Nigeria," Review of Economic Studies, 61(3): 495-526.

[41] Udry, C. (1995), "Risk and Saving in Northern Nigeria", American Economic Review, 85(5): 1287-1300.

\section{Appendix: data creation}

In this Appendix we describe how we created some of the relevant variables for our analysis: consumption, transfers and loans, school enrollment, hours of work, earnings, and prices.

\subsection{Food consumption}

We consider the three data waves collected after the program begins, in October/November 1998, May 1999, and November 1999. Considering food consumption first, households report both the expenditure in food purchased during the last week and the quantity bought. If 
expenditure on a particular item is missing, but we know the amount purchased, we consider the village median price. We compute the village price in the following way: we create household-specific prices by dividing the expenditure in food purchased during the last week by the quantity bought. If we have at least 20 household-specific prices per village, we use this information to compute median prices at the village level. Otherwise, we use either median municipality or state price (we use the lowest level of aggregation with at least 20 price observations). Once we have household-specific prices, we multiply them by quantity consumed. We do this because households produce part of the consumed food. Considering only food expenditure would underestimate the amounts actually consumed.

We use October 1998 prices to compute consumption values in May and November 1999 also. Unlike in 1998, in 1999 we know both how much food is purchased and how much is consumed, but we have no direct information on home-produced food. Hence, in order to be consistent between the three waves, we assume that in 1999 all food purchased is consumed if total consumption is smaller or equal than food purchased. If total consumption is greater than purchased goods we apply median prices to the difference, this means that either homeproduced food, or food given as a present is evaluated at market prices. Since we could not convert different measurement units in a single one, we only consider those who have bought and consumed food in the same unit (Kilo, Liter or Units). We believe that the absence of measurement conversion does not pose any major problem, since only about $1 \%$ of the sample has different measurements for the same food. Lastly, we compute adult equivalents for both food and non-food data. For this purpose, we use the adult equivalence conversion estimated by Di Maro (2004) using Progresa data. According to Di Maro, children consume on average $73 \%$ of adults. For example, to estimate individual consumption per adult equivalent for a household with one child and one adult, we divide household consumption by 1.73 .

An additional issue is how to treat missing observations. We noted that some aliments, which are not staples for rural Mexicans, have a large number of missing observations. Thus, we create three different food expenditure variables, each time dropping all households with missing observations. The first variable is aggregate expenditure in food consumption for all available categories (hence the one with the highest number of missing observations). In this way, we drop about $5 \%$ of the sample. The second one excludes industrially produced food (pastelillos en bolsa, soft drinks, coffee, sugar, vegetable oil). The third food consumption variable excludes industrially produced food, sliced bread (pan de caja), breakfast cereals, fish, and seafood. The results we show in the paper use the first consumption variable. However, they are robust to the use of these alternative variables. 
The food consumption variable we use in the paper has the following number of non-missing observations for non-poor: 5004 in October/November 1998, 3857 in May 1999, and 4286 in November 1999. 371 (i.e. about 7\%) households have zero food consumption in October 1998. Only 14 and 3 households have zero food expenditure in the May and November 1999 data, respectively. 10 households have a food consumption level larger than 10000 pesos per adult equivalent per month in the 1999 waves. We consider these extreme values to be due to measurement error, and we omit the corresponding observations from our sample. After these trimmings, we are left with the following sample sizes for non-poor households: 4633, 3839, and 4277 in October 1998, May 1999, and November 1999, respectively. We do the same for poor households, whose final samples have 10943, 9631, and 10547 households for the three waves. ${ }^{32}$ There is a drop in the valid household size in May 1999, supposedly due to a higher proportion of non-responses (this drop is not limited to the consumption variables). However, the proportion of households in treated and control areas is roughly constant over time (for non-poor, this proportion ranges from 38.8\% living in control areas in October 1998 to $39.9 \%$ in November 1999). Because of this, we believe that the smaller sample size in May 1999 does not pose attrition problems.

\subsection{Non-food consumption}

For non-food consumption, we also consider the three waves used above. The variable on nonfood consumption is only available as expenditure on particular categories of non-food items. Our measure of monthly non-food consumption is the sum of expenditures in: transport both for adults and children; tobacco; personal and house hygiene; drugs and prescriptions; doctor visits; heating (ie. wood, gas, oil); electricity; clothing and shoes; school items (ie. pencils, books). ${ }^{33}$ As for food consumption, we trim the extreme values because of possible measurement error. The value of the expenditure is then converted in real terms by applying the monthly CPI (Bank of Mexico, 2005).

When estimating the ITE on consumption, we perform a variety of robustness checks. First, we test for pre-program differences in consumption between non-poor households in

\footnotetext{
${ }^{32}$ Note that the sample sizes from the regressions may differ from the aforementioned ones because some conditioning variables may have missing observations.

${ }^{33}$ Information on expenditure on durable goods such as household appliances or home improvement is not included in our measure of non-food consumption because we observe these data only in the 1998 wave. For that year, we compute measures of both durable goods consumption and agricultural expenditure. We consider durable goods all home appliances purchased (ranging from blenders to vans), and all expenditures to improve the house. Our measure of agricultural-related expenditures refer to cost of seeds, fertilizer, pesticides, machinery, and labor, excluding land rental costs. Both measures refer to the previous 12 months.
} 
treatment and control villages using March 1998 data. ${ }^{34}$. These differences are never significant. Second, since about $2.9 \%$ and $1.5 \%$ of non-poor households report zero food and non-food consumption, respectively, we re-estimated equation (3) using consumption levels (including zeros), rather than logs, and interpreting zero consumption as measurement error or infrequent purchases, in which case OLS estimates are consistent. ${ }^{35}$ We find a significant increase in both food and non-food consumption for non-poor households in treated areas in both 1999 waves also when we include these additional households. As further robustness checks, we test whether these results are robust to a different type of trimming: for example, rather than dropping households who report a monthly food consumption larger than 10000 pesos per adult equivalent, we omit the largest percentile: the significance of the results does not change (although the point estimates are slightly different, of course). Moreover, we also estimate ITEs using the alternative measures of food consumption (described in the Appendix). Again, the magnitude and the significance of the estimates do not vary considerably. ${ }^{36}$

Table 12 provides estimates of average durable expenditure differences for the whole sample, the probability of having positive expenditures, and the difference in average expenditures for households with positive expenditure levels.

Table 12: Durable Expenditure: House Appliances/Improvements and Agricultural Production/Investment

\begin{tabular}{ccccccc}
\hline \hline & \multicolumn{2}{c}{ House appliances and improvements } & \multicolumn{3}{c}{ Production costs/investments } \\
& OLS & Probit & OLS if $>0$ & OLS & Probit & OLS if $>0$ \\
\hline$I \hat{T} E$ & 27.923 & 0.005 & 204.142 & -128.4 & -0.007 & -127.54 \\
& {$[37.405]$} & {$[0.015]$} & {$[234.422]$} & {$[106.924]$} & {$[0.006]$} & {$[109.436]$} \\
$A \hat{T} T$ & -3.614 & 0.004 & -48.861 & 23.872 & -0.006 & 25.09 \\
& {$[12.056]$} & {$[0.010]$} & {$[90.343]$} & {$[20.904]$} & {$[0.004]^{*}$} & {$[21.164]$} \\
\hline \hline
\end{tabular}

Note: The usual controls are added in the regression. The standard errors in [brackets] are clustered at the village level. $* * *, * *, *$ significant

$1,5,10 \%$ respectively.

\subsection{Hours of work and labor earnings}

The 1998 and 1999 surveys report hours of work for the sole sub-set of individuals who have a paid job, unlike the 1997 pre-program one, which collects working hour information for all

\footnotetext{
${ }^{34}$ March 1998 consumption data are not directly comparable with the other data waves, given that only aggregate expenditure categories are available, and that aggregate expenditure information often results in underreporting (Deaton (1997)). For example, there are only four food categories: vegetables and fruit; aliments of animal origin; processed foods; grains and cereals.

${ }^{35}$ Note that the $2.9 \%$ zero food consumption comes mainly from October 1998 , where about $7 \%$ of non-poor households have zero food consumption.

${ }^{36}$ Results available upon request.
} 
individuals. In 1997 there is no explicit distinction between paid and unpaid jobs. Thus, in order to create a consistent measure, we excluded self-employed, business owners and ejidatarios from the computation of hours of work. We considered as unemployed all individuals who reported not having a job in the previous week (unlike those who said that they have a job but could not work). In case of disagreement (i.e. individuals reporting they do not have a job, but having a positive number of hours worked) we included the reported work time.

These variables are very noisy measures of work time and earnings, as at times we have to impute monthly earnings from daily, weekly or annual wages. To reduce measurement error, we trim the top and bottom percentile. However, we do not expect the type of error in measurement to differ systematically between households in treatment and control villages. Moreover, when used as dependent variable, classic measurement error affects only the precision, but not the consistency of the coefficient estimates. We try to offset this lack of precision by including a large set of conditioning variables.

\subsection{Prices}

Prices refer to the food and non-food goods used to compute the value of consumption. There are 57 different goods, but only food prices are available before the program begins, in March 1998. Thus, we use the 36 food prices available both before and during the program implementation to provide DD estimates of the effect of Progresa. In October 1998 and May 1999 we have up to two prices for each good. When two different prices for the same good are available, we compute the mean village price. Table 13 provides a list of the goods used in the DD analysis of the program effect.

We find a small positive effect on some food prices in October 1998. Prices of onions (p2), lemons (p8), eggs (p26), and coffee (p34) are significantly higher in treatment than in control areas. At the same time, though, the price of fish (p23) is significantly lower. Despite the fact that onions, eggs, and coffee are commonly consumed foods (Hoddinott et al., (2000)), we do not expect these price changes to increase the cost of the food basket substantially, because prices of staples such as rice, beans, corn, and chicken do not change. Second, there is no price change in the later waves. Third, if we consider the pooled waves, the prices of 6 items increase, while the prices of 3 goods decrease in the observed time, out of a total of 36 items by 3 waves. This amounts to roughly a change in $8 \%$ of good prices. We believe that, perhaps with the exception of a minor price increase for some goods in the end of 1998, Progresa does not significantly change prices of treatment areas. ${ }^{37}$

\footnotetext{
${ }^{37}$ There is a large number of missing observations. Since there are 506 villages observed in 4 different points
} 
Table 13: Food Prices Used to Compute Diff-Diff Estimates of Program Effect on Prices

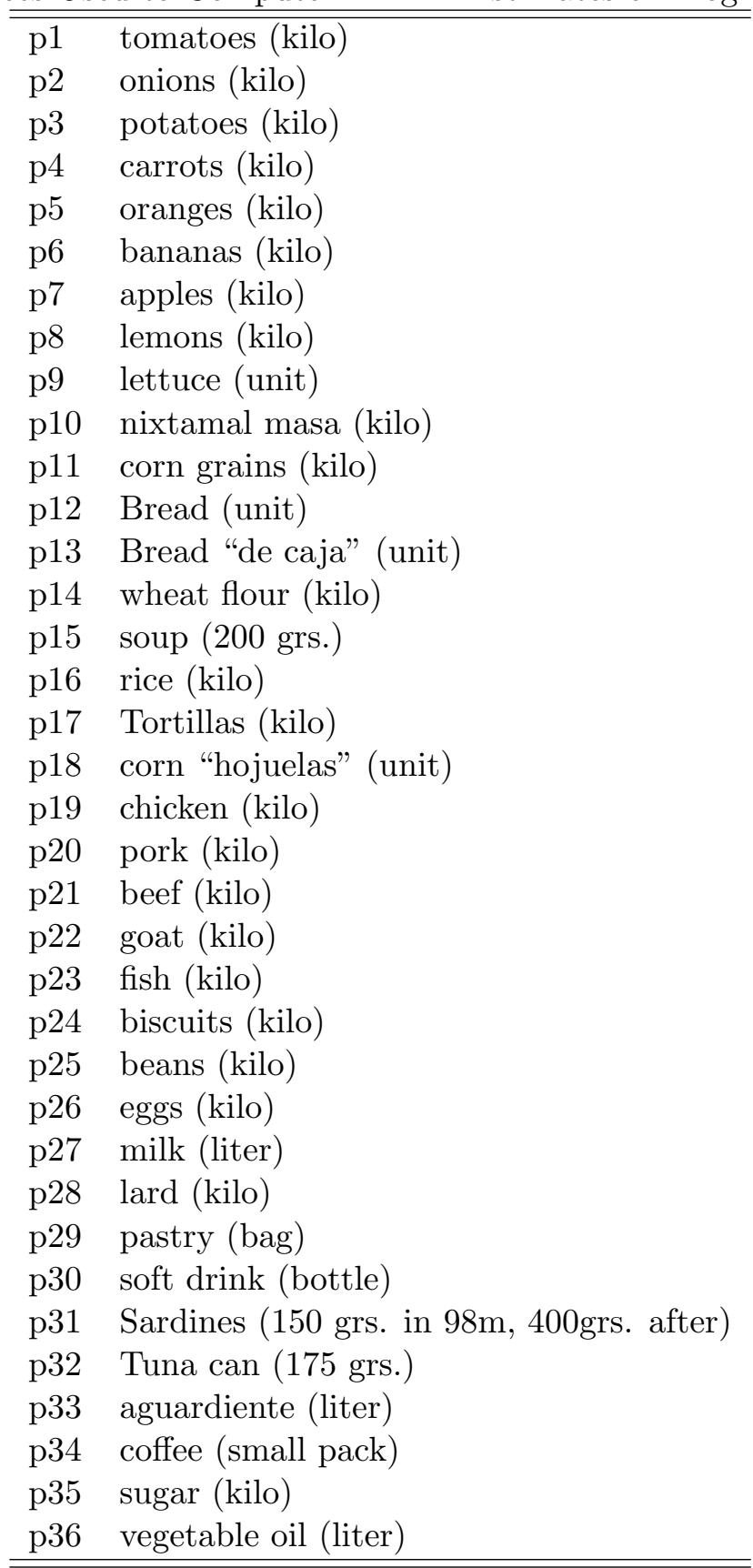


As a further robustness check, we considered all 57 different (food and non-food) goods available in the 3 waves collected after the beginning of the program. We pooled prices, creating a price basket that gives equal weight of one to each good. We then regressed this synthetic price indicator on a dummy for treatment and control villages, obtaining cross sectional estimates of the effect of Progresa on prices. Also in this case we reject the hypothesis that prices differ significantly between the two village groups. ${ }^{38}$

Table 14: Difference in Differences Estimates of the Effect of Progresa on Village Prices

\begin{tabular}{|c|c|c|c|c|c|c|c|c|c|}
\hline & p1 & p2 & p3 & $\mathrm{p} 4$ & $\mathrm{p} 5$ & $\mathrm{p} 6$ & $\mathrm{p} 7$ & p8 & p9 \\
\hline \multirow[t]{2}{*}{$\mathrm{T}$} & 0.0826 & -1.1782 & -0.0435 & -0.5462 & 0.1246 & -0.0443 & -0.0414 & -1.3424 & -1.6077 \\
\hline & {$[0.2582]$} & {$[0.4387]^{* * *}$} & {$[0.2357]$} & [0.4391] & {$[0.2012]$} & {$[0.1677]$} & [0.3895] & {$[0.9675]$} & [1.2532] \\
\hline \multirow[t]{2}{*}{$\mathrm{T}^{*} 1998$ Oct. } & 0.095 & 1.2498 & 0.0609 & 0.877 & -0.5583 & 0.2174 & -0.2832 & 1.8117 & 1.6452 \\
\hline & {$[0.3840]$} & {$[0.4985]^{* *}$} & [0.3974] & [0.6473] & [0.3953] & {$[0.2851]$} & {$[0.6732]$} & {$[1.0401]^{*}$} & {$[1.2807]$} \\
\hline \multirow[t]{2}{*}{ T*1999 May } & 0.0804 & 0.781 & -0.3818 & 0.1531 & 0.0866 & -0.3466 & -0.1483 & 1.1914 & 1.2465 \\
\hline & {$[0.7453]$} & [0.5417] & [0.3099] & {$[0.5599]$} & {$[0.2987]$} & {$[0.2831]$} & {$[0.7589]$} & [1.0111] & {$[1.2876]$} \\
\hline \multirow[t]{2}{*}{ T*1999 Nov. } & -0.8173 & 1.3505 & -1.3779 & 1.5488 & -1.6462 & -1.1732 & -0.325 & 3.2171 & 2.0641 \\
\hline & {$[0.3489]^{* *}$} & {$[0.8422]$} & [0.8913] & [2.5669] & {$[0.6641]^{* *}$} & [1.4749] & [0.5746] & [2.2543] & [1.3830] \\
\hline \multirow[t]{2}{*}{ Obs. } & 1034 & 990 & 948 & 369 & 678 & 698 & 426 & 548 & 413 \\
\hline & p10 & p11 & p12 & $\mathrm{p} 13$ & p14 & p15 & p16 & p17 & p18 \\
\hline \multirow[t]{2}{*}{$\bar{T}$} & -0.5039 & 0.0057 & -0.3148 & -1.69 & 0.0501 & -0.3291 & -0.1483 & 0.0265 & 0.8105 \\
\hline & {$[0.3412]$} & {$[0.2665]$} & [0.3250] & [1.3105] & [0.1785] & {$[0.4101]$} & [0.1409] & [0.1299] & [0.9233] \\
\hline \multirow[t]{2}{*}{$\mathrm{T}^{*} 1998$ Oct. } & 0.4998 & 0.2034 & 0.3913 & 1.4979 & -0.0945 & 0.2555 & -0.1047 & 0.0531 & 0.1171 \\
\hline & {$[0.4262]$} & {$[0.3482]$} & {$[0.3511]$} & [1.3912] & {$[0.2497]$} & {$[0.4202]$} & {$[0.1859]$} & {$[0.1758]$} & [1.3075] \\
\hline \multirow[t]{2}{*}{ T*1999 May } & 0.2958 & -0.428 & 0.0864 & 2.0122 & -0.2671 & 0.264 & 0.1945 & 0.3573 & 0.694 \\
\hline & [0.4109] & [0.3291] & {$[0.6539]$} & [1.3717] & [0.3055] & {$[0.4162]$} & {$[0.2806]$} & {$[0.3769]$} & [1.5655] \\
\hline \multirow[t]{2}{*}{ T*1999 Nov. } & 0.8789 & 2.5907 & 4.0232 & 0.4852 & 9.1043 & -0.3298 & -0.569 & -0.4817 & -1.6231 \\
\hline & {$[4.4228]$} & [1.7468] & [9.9232] & [1.4638] & [9.2109] & [0.5394] & [0.5809] & {$[0.4022]$} & [1.1575] \\
\hline \multirow[t]{2}{*}{ Obs. } & 365 & 640 & 750 & 390 & 678 & 1233 & 1375 & 424 & 565 \\
\hline & p19 & p20 & p21 & $\mathrm{p} 22$ & p23 & p24 & p25 & p26 & p27 \\
\hline \multirow[t]{2}{*}{$\mathrm{T}$} & -0.2255 & -0.5765 & -0.1634 & -15.4505 & -1.6939 & -0.15 & -0.3617 & -0.9393 & -0.34 \\
\hline & {$[0.6422]$} & [0.9607] & [1.2435] & {$[9.0361]^{*}$} & [2.0772] & [0.2455] & {$[0.1621]^{* *}$} & {$[0.3405]^{* * *}$} & [0.2410] \\
\hline \multirow[t]{2}{*}{$\mathrm{T}^{*} 1998$ Oct. } & -1.8291 & -1.8317 & -1.3589 & 13.7839 & -6.8775 & 0.1938 & 0.0172 & 1.1282 & 0.3435 \\
\hline & [1.3035] & [1.6762] & [3.2008] & [11.1087] & {$[3.9947]^{*}$} & {$[0.2641]$} & {$[0.3141]$} & {$[0.4336]^{* * *}$} & [0.3052] \\
\hline \multirow[t]{2}{*}{ T*1999 May } & -0.5113 & 0.9343 & 1.1377 & 12.0755 & 5.714 & 0.129 & 0.3623 & 0.5862 & 0.3434 \\
\hline & {$[0.8389]$} & [1.2960] & [1.7734] & [11.5156] & [5.6679] & {$[0.2637]$} & {$[0.2650]$} & [0.4429] & [0.4402] \\
\hline \multirow[t]{2}{*}{ T*1999 Nov. } & -1.2303 & 0.9294 & -0.0991 & 15.3242 & 3.4506 & 0.1216 & -0.2787 & 0.4151 & -2.3614 \\
\hline & [2.2299] & [1.1187] & [1.2644] & {$[9.0350]^{*}$} & [2.7004] & [0.4785] & [0.4876] & {$[0.7810]$} & [3.3976] \\
\hline \multirow[t]{2}{*}{ Obs. } & 486 & 566 & 313 & 334 & 344 & 1375 & 1194 & 1206 & 833 \\
\hline & p28 & p29 & p30 & p31 & p32 & p33 & p34 & p35 & p36 \\
\hline \multirow[t]{2}{*}{$\mathrm{T}$} & -0.0689 & -0.1552 & 0.0916 & -0.0645 & -0.0312 & -0.3793 & -1.5319 & -0.1483 & -0.1349 \\
\hline & {$[0.3556]$} & [0.1894] & {$[0.2142]$} & {$[0.1266]$} & [0.0939] & {$[0.7805]$} & {$[0.5373]^{* * *}$} & {$[0.0950]$} & {$[0.1196]$} \\
\hline \multirow[t]{2}{*}{ T*1998 Oct. } & -0.0634 & 0.1684 & -0.151 & 0.1084 & -0.0026 & 1.2379 & 2.2448 & 0.1084 & 0.1579 \\
\hline & [0.5199] & {$[0.2163]$} & {$[0.2647]$} & {$[0.1734]$} & [0.1331] & [1.1330] & {$[0.7657]^{* * *}$} & {$[0.1324]$} & [0.1828] \\
\hline \multirow[t]{2}{*}{ T*1999 May } & -0.3067 & -0.068 & -0.3152 & 0.542 & 0.2061 & 1.5668 & 0.3668 & 0.1521 & 0.1635 \\
\hline & {$[0.5517]$} & [0.3063] & [0.3013] & {$[0.2638]^{* *}$} & [0.1485] & [1.5627] & [0.7374] & [0.2031] & [0.1800] \\
\hline \multirow[t]{2}{*}{ T*1999 Nov. } & 0.5788 & 0.6931 & 6.3978 & -0.4729 & -0.3143 & 0.3309 & -0.0825 & 0.6451 & 2.5376 \\
\hline & {$[0.7721]$} & [0.9239] & [10.4329] & [0.5949] & [10.0995] & [0.8828] & [6.4283] & [0.7407] & [2.2574] \\
\hline Obs. & 634 & 488 & 922 & 1272 & 1021 & 757 & 636 & 1431 & 1219 \\
\hline
\end{tabular}


Table 15: Cross Sectional Estimates of Differences in Participation to Alternative Aid Programs

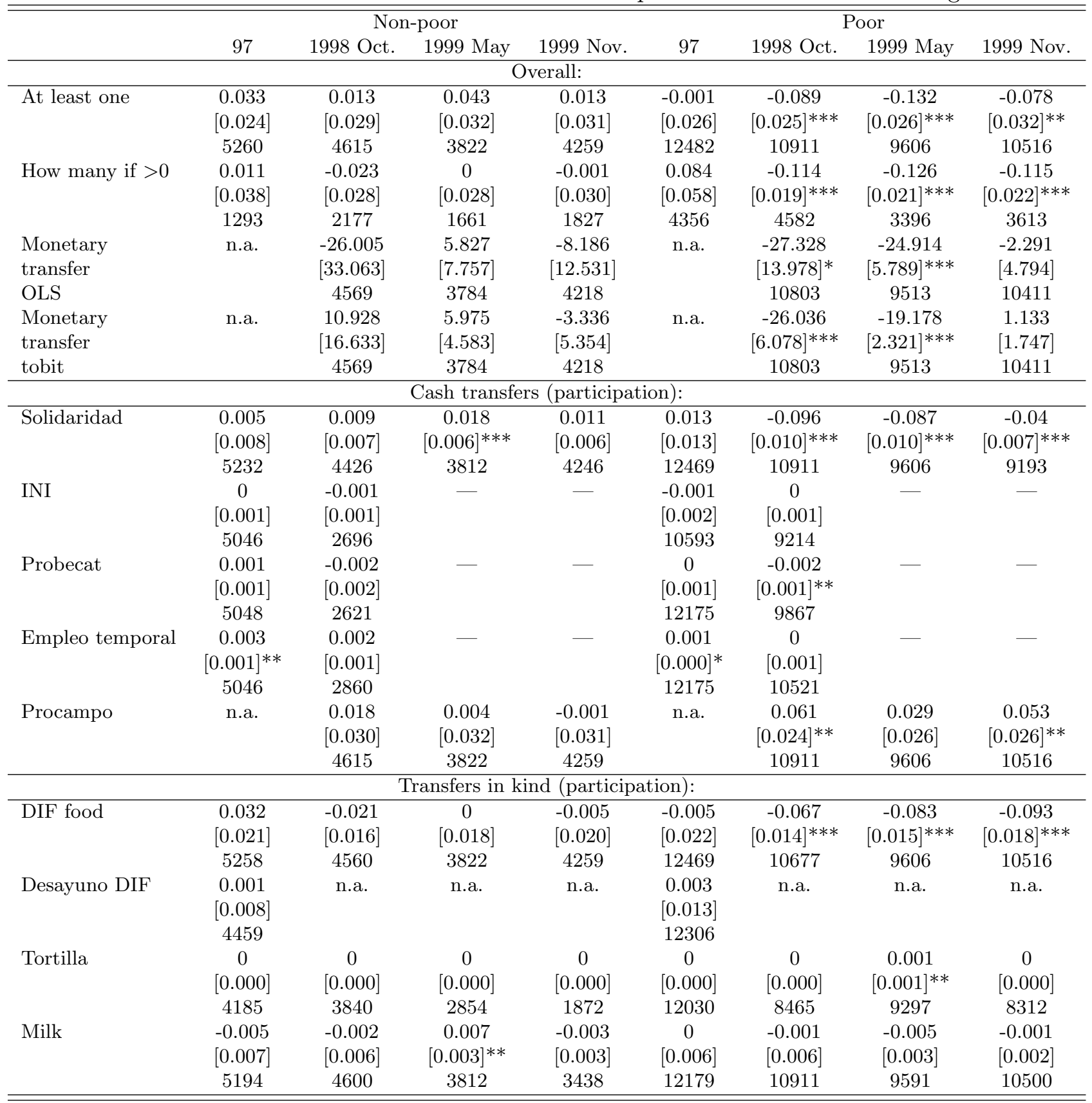

Note: The likelihood of receiving individual program transfers is estimated by Probit. The total monetary transfer received is estimated both by OLS and by tobit. Standard errors clustered at the village level (apart from tobit estimates). $* * *, * *, *$ significant at $1,5,10 \%$ respectively. 


\subsection{Alternative program receipt}

Table 15 shows estimates of differences in participation to alternative aid programs. The first 4 rows of the Table present estimates of the differences in the aggregate measures. The following 8 rows show estimates of the differences in participation to the five cash transfer programs, and the three in kind programs. All these variables are at the household level, and refer to the month before the interviews took place. We find that there are no differences in alternative welfare receipt in 1997, with the exception of a slightly higher participation to the temporary employment program in treatment areas (for both poor and non-poor households). Thus, we rely on cross-sectional estimates of the differences for the remaining three data waves.

It is possible that non-poor participation to alternative welfare programs may have increased for all control villages: for example, households in control villages know of the existence of Progresa and may feel deprived, hence participate more to alternative programs. Alternatively, program officials may become more "generous" in communities excluded from Progresa. This increase in welfare receipts in control villages would be compatible with the results presented in Table 15. For instance, the absence of significant differences for non-poor may be consistent with equally increased participation rates in both types of villages. Similarly, part of the apparent decrease in receipt for treatment poor may actually be due to increased participation in control villages. In any case, note that if non-poor alternative program take-up increased equally in both treatment and control areas, it still would not explain why non-poor consumption is higher in treatment than in control villages.

One way to observe whether alternative programs take-up surged in both types of villages is to compare trends in these programs' pre- and during-Progresa participation rates. If we observed a substantial peak in 1998 and 1999 non-poor participation, compared to the 1997 levels, we may suspect that this is partly an indirect effect of Progresa in both treatment and control villages. Of course the supposed increase in welfare participation may as well be due to exogenous reasons. Table 16 compares average participation rates over time for Solidaridad, DIF food, Liconsa milk, and Tortilla. These are the only programs we observe for all 4 data waves. The comparison of program take-up rates over time clearly shows that there is no surge in participation in control areas after the beginning of Progresa. In fact, participation rates slowly decrease over time, in general.

in time, each price should have about 2000 observations. Instead, the non-missing observations range between 313 and 1375.

${ }^{38}$ Results available upon request. 
Table 16: Average Monthly Participation Rates to Selected Alternative Aid Programs

\begin{tabular}{|c|c|c|c|c|}
\hline & 1997 & 1998 Oct. & 1999 May & 1999 Nov. \\
\hline & \multicolumn{4}{|c|}{ Solidaridad } \\
\hline \multirow[t]{2}{*}{ NP control } & 0.081 & 0.074 & 0.053 & 0.040 \\
\hline & $(0.273)$ & $(0.262)$ & $(0.224)$ & $(0.197)$ \\
\hline \multirow[t]{2}{*}{ NP treatment } & 0.079 & 0.077 & 0.079 & 0.052 \\
\hline & $(0.270)$ & $(0.266)$ & $(0.269)$ & $(0.222)$ \\
\hline \multirow[t]{2}{*}{ P control } & 0.141 & 0.136 & 0.121 & 0.049 \\
\hline & $(0.349)$ & $(0.343)$ & $(0.326)$ & $(0.216)$ \\
\hline \multirow[t]{3}{*}{$\mathrm{P}$ treatment } & 0.153 & 0.026 & 0.005 & 0.003 \\
\hline & $(0.360)$ & $(0.160)$ & $(0.071)$ & $(0.057)$ \\
\hline & \multicolumn{4}{|c|}{ DIF food } \\
\hline \multirow[t]{2}{*}{ NP control } & 0.112 & 0.099 & 0.100 & 0.094 \\
\hline & $(0.316)$ & $(0.299)$ & $(0.300)$ & $(0.292)$ \\
\hline \multirow[t]{2}{*}{ NP treatment } & 0.136 & 0.072 & 0.092 & 0.090 \\
\hline & $(0.343)$ & $(0.259)$ & $(0.289)$ & $(0.286)$ \\
\hline \multirow[t]{2}{*}{$\mathrm{P}$ control } & 0.153 & 0.116 & 0.112 & 0.144 \\
\hline & $(0.360)$ & $(0.321)$ & $(0.315)$ & $(0.351)$ \\
\hline \multirow[t]{3}{*}{$\mathrm{P}$ treatment } & 0.140 & 0.044 & 0.025 & 0.024 \\
\hline & $(0.347)$ & $(0.206)$ & $(0.156)$ & $(0.154)$ \\
\hline & \multicolumn{4}{|c|}{ Tortilla } \\
\hline \multirow[t]{2}{*}{ NP control } & 0.000 & 0.001 & 0.001 & 0.001 \\
\hline & $(0.022)$ & $(0.024)$ & $(0.026)$ & $(0.034)$ \\
\hline \multirow[t]{2}{*}{ NP treatment } & 0.002 & 0.006 & 0.009 & 0.004 \\
\hline & $(0.039)$ & $(0.077)$ & $(0.095)$ & $(0.059)$ \\
\hline \multirow[t]{2}{*}{$\mathrm{P}$ control } & 0.001 & 0.001 & 0.001 & 0.001 \\
\hline & $(0.033)$ & $(0.031)$ & $(0.029)$ & $(0.027)$ \\
\hline \multirow[t]{3}{*}{$\mathrm{P}$ treatment } & 0.001 & 0.002 & 0.003 & 0.002 \\
\hline & $(0.030)$ & $(0.045)$ & $(0.050)$ & $(0.045)$ \\
\hline & \multicolumn{4}{|c|}{ Liconsa milk } \\
\hline \multirow[t]{2}{*}{ NP control } & 0.037 & 0.027 & 0.012 & 0.012 \\
\hline & $(0.189)$ & $(0.162)$ & $(0.109)$ & $(0.108)$ \\
\hline \multirow[t]{2}{*}{ NP treatment } & 0.029 & 0.028 & 0.017 & 0.009 \\
\hline & $(0.166)$ & $(0.164)$ & $(0.130)$ & $(0.096)$ \\
\hline \multirow[t]{2}{*}{ P control } & 0.034 & 0.034 & 0.016 & 0.009 \\
\hline & $(0.181)$ & $(0.182)$ & $(0.124)$ & $(0.097)$ \\
\hline \multirow[t]{2}{*}{$\mathrm{P}$ treatment } & 0.032 & 0.034 & 0.010 & 0.008 \\
\hline & $(0.176)$ & $(0.180)$ & $(0.099)$ & $(0.088)$ \\
\hline
\end{tabular}




\subsection{Shocks}

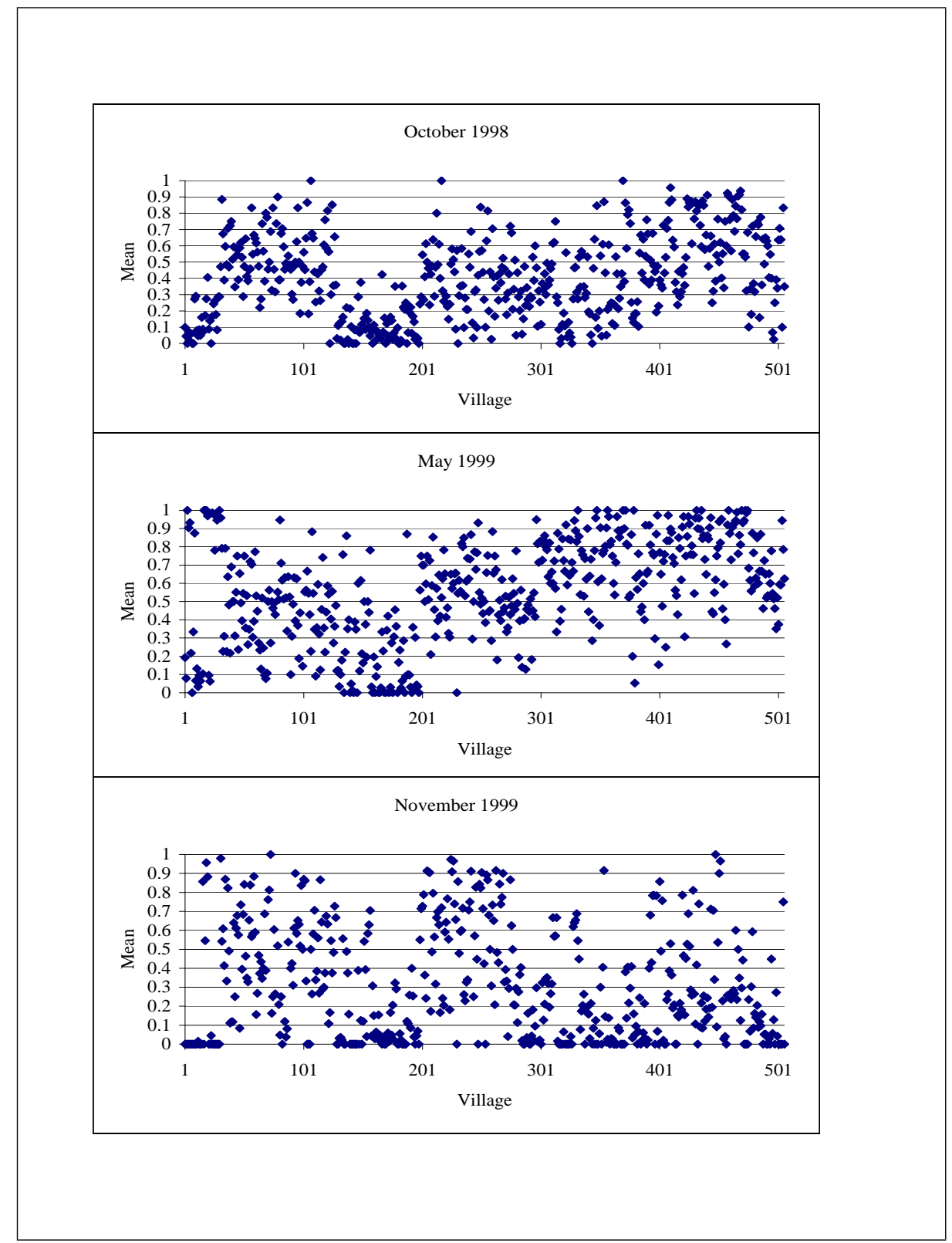

Figure 2: Mean of the Shocks at the Village Level

We observe two different measures of shock in our sample. The data record whether, in the six months preceding the interview, the household has been hit by any of the following types of natural disasters: drought, flood, frost, fire, plague, earthquake, and hurricane. We also know whether any of these natural disasters caused a damage to the household, such as: loss of land, harvest, housing, property, tools, animals, and household members; casualties, and members migrating to find jobs elsewhere. We create two different dummy variables. One records whether the household has been hit by any natural disaster. The second one, instead, considers whether the household suffered from any of the above losses. The natural disaster 
dummy may include households who did not incur any loss because of the natural disaster. However, we suspect it is more likely to be unrelated to household characteristics than the second variable. For instance, loss of land and animals are conditional on their ownership by the households, while the decision to migrate is constrained by the availability of savings to finance the trip. The results showed in the paper use our preferred shock variable, the natural disaster dummy. However, our estimates do not vary substantially when we use the loss dummy. ${ }^{39}$ One potential shortcoming of this variable may be shocks hitting entire villages, leaving no within-village variation. For example, it is unlikely that an earthquake may hit only half a village. However, Figure 2 shows that this is not the case: when we plot within-village proportions of households hit by shocks, we notice that only in very few cases the entire village is hit.

In order to compare indirect program effects for households hit and not hit by a shock, we require that shocks are random both between and within villages. To insure that this is the case, we perform three tests. First, we check whether shocks hit treated and control areas differentially, for all households, and for non-poor and poor families separately. The top panel of Table 17 presents the partial effects from a probit regression of the probability of being hit by a shock on village area dummies, and shows that the estimates are never statistically significant. Second, to test whether more vulnerable households are more likely to suffer from adverse shocks, we check whether households with lower pre-program consumption are more likely to suffer future shocks. We regress March 1998 log food and non-food consumption on the October 1998, May 1999, and November 1999 shock dummies, alternatively. We repeat this exercise for both the whole sample and for poor and non-poor separately. The middle panel in Table 17 presents the estimates of the shock dummy coefficients, which are never significant. Thus, we cannot reject the hypothesis that the average pre-program consumption levels are the same for households hit and not hit by adverse shocks. Lastly, we want to test whether average pre-program consumption levels are the same for the four groups defined by village of residence (treatment or control, i.e. $T=1$ or $T=0$ ) and shock status (hit or not hit, i.e. $S=1$ or $S=0$ ). We consider non-poor and poor households separately, and regress log consumption on dummies that group households accordingly (one dummy for $T=1$ and $S=0$, one for $T=1$ and $S=1$, a third one for $T=0$ and $S=0$ ) and test the hypotheses that the coefficients of these three dummies are jointly equal to zero, interpreting the null as evidence of the randomness of the idiosyncratic shocks. As before, we repeat this exercise three times, since we have shock data for each of the three semesters we consider. We report the values of the

\footnotetext{
${ }^{39}$ Results available upon request.
} 
Table 17: Tests of the Randomness of Idiosyncratic Shocks 1998 Oct. 1999 May 1999 Nov.

\begin{tabular}{lccc}
\hline \hline & 1998 Oct. & 1999 May & 1999 Nov. \\
\hline & & & \\
ALL & Difference in average shock level by village type \\
& -.0223 & -0.0225 & -0.0027 \\
Obs. & {$[0.0178]$} & {$[0.0196]$} & {$[0.0224]$} \\
& 13981 & 12130 & 13297 \\
NP & -0.0023 & 0.0031 & \\
& {$[0.0276]$} & {$[0.0296]$} & 0.0304 \\
Obs. & 4209 & 3502 & {$[0.0345]$} \\
& & & 3890 \\
P & -0.0138 & 0.0379 & 0.0087 \\
& {$[0.0253]$} & {$[0.0281]$} & {$[0.0303]$} \\
Obs. & 9772 & 8628 & 9407 \\
\hline
\end{tabular}

Difference in pre-program consumption by shock status

\begin{tabular}{lcccccc} 
& Food & Non-Food & Food & Non-Food & Food & Non-Food \\
\hline ALL & -0.0008 & 0.017 & -0.007 & -0.0189 & 0.004 & 0.030 \\
& {$[0.010]$} & {$[0.018]$} & {$[0.120]$} & {$[0.021]$} & {$[0.012]$} & {$[0.022]$} \\
Obs. & 13981 & 13794 & 12130 & 11974 & 13297 & 13135 \\
& & & & & & \\
NP & -0.011 & 0.005 & -0.002 & -0.035 & -0.008 & -0.025 \\
& {$[0.019]$} & {$[0.037]$} & {$[0.021]$} & {$[0.044]$} & {$[0.023]$} & {$[0.038]$} \\
Obs. & 4209 & 4145 & 3502 & 3448 & 3890 & 3838 \\
& & & & & & \\
P & 0.001 & 0.021 & -0.012 & -0.015 & 0.009 & $0.051^{*}$ \\
& {$[0.012]$} & {$[0.023]$} & {$[0.014]$} & {$[0.024]$} & {$[0.014]$} & {$[0.027]$} \\
Obs. & 9772 & 9649 & 8628 & 8526 & 9407 & 9297 \\
\hline
\end{tabular}

Difference in pre-program consumption by shock status and village type

\begin{tabular}{lcccccc} 
& Food & Non-Food & Food & Non-Food & Food & Non-Food \\
\hline NP & 0.56 & 0.10 & $2.56^{*}$ & $2.41^{*}$ & 0.15 & 0.53 \\
Obs. & 4196 & 4132 & 3493 & 3493 & 3879 & 3827 \\
& & & & & & \\
P & 0.12 & 1.00 & 0.25 & 1.31 & 0.14 & 1.67 \\
Obs. & 9757 & 9634 & 8614 & 8512 & 9393 & 9283 \\
\hline \hline
\end{tabular}

Note: The usual set of pre-program controls, including average shock intensity at the village level, is added to all regressions. Standard errors clustered at the village level. ${ }^{* *},{ }^{* *}, *$ are $1,5,10 \%$ significance levels. 
F-tests in the lower panel of Table 17. We add the usual set of pre-program controls, including average shock intensity at the village level, to all regressions in the Table. Note that the weak significance of the F test for May 1999 shocks disappears as we change the set of conditioning variables. Thus, also this third test confirms that these adverse shocks hit the households in our sample in a random way.

Table 18: Effect of Progresa on Credit for the Poor, by Shock

\begin{tabular}{|c|c|c|c|c|c|c|}
\hline & \multicolumn{2}{|c|}{1998 Oct. } & \multicolumn{2}{|c|}{1999 May } & \multicolumn{2}{|c|}{1999 Nov. } \\
\hline & Probit & Tobit & Probit & Tobit & Probit & Tobit \\
\hline & \multicolumn{6}{|c|}{ Total credit resources: } \\
\hline$I T \hat{E}^{S 0}$ & $\begin{array}{c}0.0066 \\
{[0.0104]}\end{array}$ & $\begin{array}{l}1.5004 \\
{[2.182]}\end{array}$ & & & & \\
\hline$I T \hat{E}^{S 1}$ & $\begin{array}{l}-0.0029 \\
{[0.0104]}\end{array}$ & $\begin{array}{r}-0.7207 \\
{[2.504]}\end{array}$ & & & & \\
\hline$I T \hat{E}^{S 1}-I T \hat{E}^{S 0}$ & $\begin{array}{c}-0.0095 \\
{[0.133]}\end{array}$ & $\begin{array}{l}-2.2211 \\
{[3.2663]}\end{array}$ & & & & \\
\hline \multirow[t]{2}{*}{ Obs. } & 10893 & 10885 & & & & \\
\hline & \multicolumn{6}{|c|}{ Loans: } \\
\hline$I T \hat{E}^{S 0}$ & $\begin{array}{c}0.0048 \\
{[0.0059]}\end{array}$ & $\begin{array}{c}0.7434 \\
{[0.6643]}\end{array}$ & $\begin{array}{l}-0.0058 \\
{[0.0062]}\end{array}$ & $\begin{array}{l}-0.7343 \\
{[0.9255]}\end{array}$ & & \\
\hline$I T \hat{E}^{S 1}$ & $\begin{array}{l}-0.0018 \\
{[0.0053]}\end{array}$ & $\begin{array}{l}-0.6332 \\
{[0.7313]}\end{array}$ & $\begin{array}{l}-0.0095 \\
{[0.0066]}\end{array}$ & $\begin{array}{c}-1.7928 \\
{[0.7903]^{* *}}\end{array}$ & & \\
\hline$I T \hat{E}^{S 1}-I T \hat{E}^{S 0}$ & $\begin{array}{l}-0.0066 \\
{[0.0073]}\end{array}$ & $\begin{array}{l}-1.3766 \\
{[0.9627]}\end{array}$ & $\begin{array}{l}-0.0037 \\
{[0.0059]}\end{array}$ & $\begin{array}{l}-1.0585 \\
{[1.1142]}\end{array}$ & & \\
\hline Obs. & 10893 & 10889 & 9478 & 9569 & & \\
\hline & \multicolumn{6}{|c|}{ Monetary transfers from family and friends: } \\
\hline$I T \hat{E}^{S 0}$ & $\begin{array}{l}-0.0020 \\
{[0.0031]}\end{array}$ & $\begin{array}{l}-0.7036 \\
{[1.2475]}\end{array}$ & & & $\begin{array}{c}0.0031 \\
{[0.0018]^{*}}\end{array}$ & $\begin{array}{c}1.839 \\
{[1.031]^{*}}\end{array}$ \\
\hline$I T \hat{E}^{S 1}$ & $\begin{array}{c}0.0015 \\
{[0.0041]}\end{array}$ & $\begin{array}{l}-0.147 \\
{[1.574]}\end{array}$ & & & $\begin{array}{l}-0.0018 \\
{[0.0022]}\end{array}$ & $\begin{array}{l}-0.7363 \\
{[1.5037]}\end{array}$ \\
\hline$I T \hat{E}^{S 1}-I T \hat{E}^{S 0}$ & $\begin{array}{c}0.0035 \\
{[0.0047]}\end{array}$ & $\begin{array}{c}0.5566 \\
{[1.9193]}\end{array}$ & & & $\begin{array}{c}-0.0049 \\
{[0.0027]^{*}}\end{array}$ & $\begin{array}{l}-2.5753 \\
{[1.7884]}\end{array}$ \\
\hline Obs. & 10894 & 10741 & & & 10500 & 10361 \\
\hline & \multicolumn{6}{|c|}{ In-kind transfers from family and friends: } \\
\hline$I T E^{S 0}$ & $\begin{array}{l}-0.0007 \\
{[0.0021]}\end{array}$ & & & & $\begin{array}{c}-0.0062 \\
{[0.0019]^{* * *}}\end{array}$ & \\
\hline$I T \hat{E}^{S 1}$ & $\begin{array}{l}-0.0012 \\
{[0.0026]}\end{array}$ & & & & $\begin{array}{l}0.0002 \\
{[0.003]}\end{array}$ & \\
\hline$I T \hat{E}^{S 1}-I T \hat{E}^{S 0}$ & $\begin{array}{c}0.0005 \\
{[0.0033]}\end{array}$ & & & & $\begin{array}{c}0.0064 \\
{[0.0033]^{*}}\end{array}$ & \\
\hline Obs. & 10894 & & & & 10500 & \\
\hline
\end{tabular}

Note: Top 1\% of positive values is trimmed in the Tobit. The usual controls are added in the regression. The standard errors in [brackets] are clustered at the village level in the Probit regressions. ${ }^{* * *},{ }^{* *},{ }^{*}$ significant $1,5,10 \%$ respectively. 


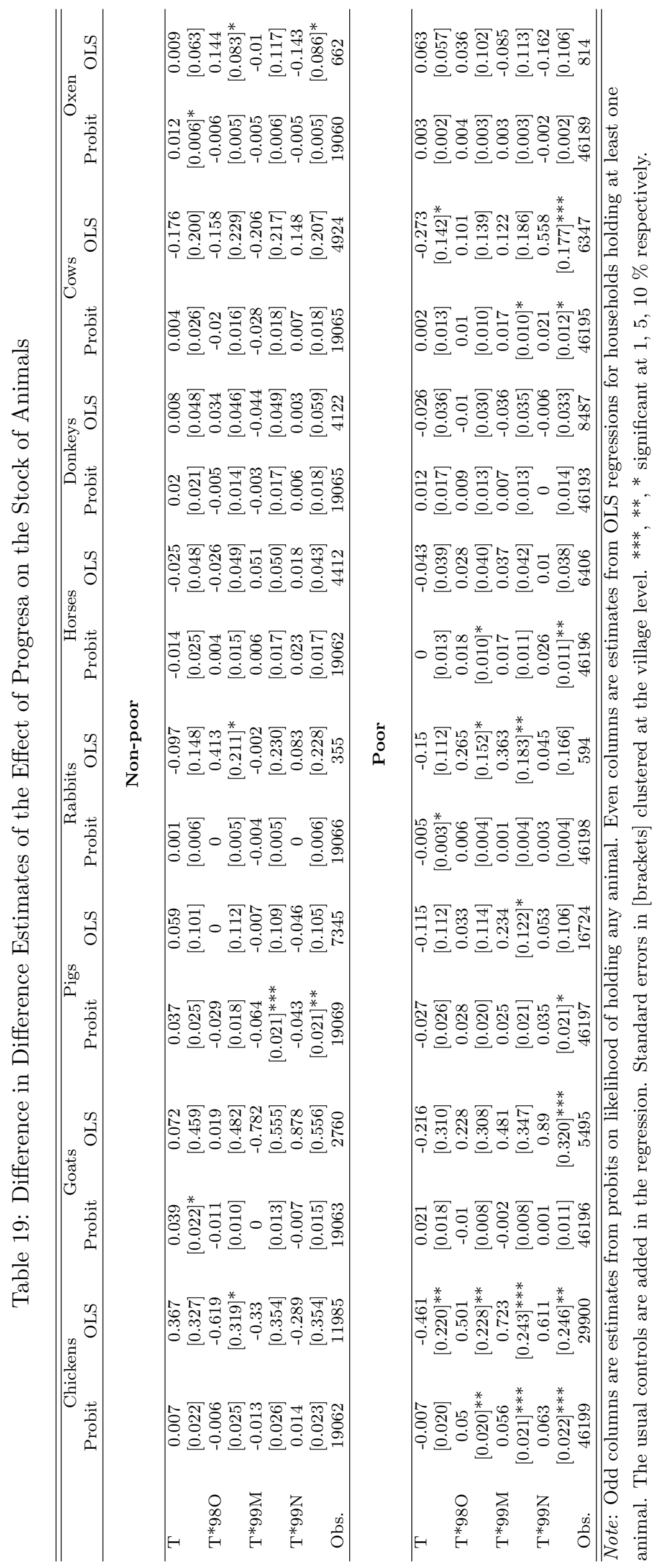

